\title{
Barriers and Facilitators for Execution of Nursing Process Among Nurses in Mayo Hospital Lahore, Pakistan
}

\author{
Rukhsana Bibi Muhammad Ali Mehwish Javeed \\ Sharif College of Nursing, Sharif Medical City Lahore Pakistan
}

\begin{abstract}
Background: Nursing process is a global concept, which builds the base of nursing as profession. The nursing process is used in many hospitals for implementation of nursing efforts. Nursing has always directed to provide comfort, care, and assurance to the patients in order to keep them healthy. The nursing care may involve many activities ranging from holding a hand of the patient to carrying out complicated technical procedures. Objectives: objective of this study is to determine barriers and facilitators which nurses face during implementation of nursing process in hospitals. Methodology: Descriptive cross sectional study design with a sample size of 124 participants which were selected through convenient sampling in Mayo hospital Lahore. Results: results of this study were carried out using SPSS version 21. From 100\% participants $0.8 \%$ of the participants were male and $99.2 \%$ participants were female. $89.5 \%$ participants have good knowledge in nursing process and $67.7 \%$ participants practice nursing process often. 84.68\% participants revealed that Hospital management needs to be progressive on benefits of nursing process. $87.9 \%$ participants stated that they face barriers related to insufficient resources. $65.3 \%$ participants were agree admitted that nursing process is time consuming. $62.9 \%$ participants were not agree about having enough time for execution of process. $79.8 \%$ participants admitted that they have got this knowledge during training life. Conclusion: This study concluded that nurses have a worthy knowledge about nursing process. Most nurses practice it often and others who cannot implement it may face barriers like shortage of time, inadequate resources and some managerial inadequacies.
\end{abstract}

Keywords: Execution of Nursing Process. Barriers \& facilitators.

DOI: $10.7176 / \mathrm{JHMN} / 77-07$

Publication date:July $31^{\text {st }} 2020$

\section{CHAPTER 1}

\section{INTRODUCTION}

Problem Statement:

Nursing Process ensures the provision of good quality nursing care through nursing care plans, which include assessment, planning, and application of care through implementation and at the last to evaluate about results of care being provided. There is a need to discuss barriers and facilitators which are faced for implementation of nursing process.

Nursing process is an international thought, which forms the base of nursing as profession. The nursing process is used in most hospitals for implementation of nursing efforts. (Momoh \& Chukwu, 2010). Nursing Procedure is an organized method, in which nurses activates rational thinking, critical thinking and basic perceptive to provide effective nursing care for patients. It is a problem solving method and confirmation based technique, which contains distinct phases, and it is a goal -directed practice for proper care of patients (Mahmoud \& Bayoumy, 2014).

Nursing has always aimed to keep people healthy and provide comfort, care, and assurance to the patients. The nursing process is a combination of simple and complicated tasks. The main focus of nursing care is the person who receives care and includes the physical, emotional, social and spiritual health of that person; therefore it is known as caring of others. Nurses therefore needs many things for provision of care and proper documentation of findings e.g. nurses develop nursing care plan to meet all the demands of patients on hand. (Mbithi, Mwenda, \& Karonjo, 2018).

The nursing process is in use for over 30 years globally, that was previously introduced as a systemic method of planning nursing care. The nursing process is a systematic methodology of assessing, diagnosing, planning, carrying out and evaluating individualized care for clients either in state of health or illness. Based on the scientific problem-solving method, it establishes the frame for nursing practice. The nursing process is the foundation of current practice of an important element of nursing education as well as a point of reference in providing nursing care around the globe. Possibly it is important to all nursing actions, applicable in any setting and within any frame. However not all steps are implemented systemically.

Previous studies have shown that in most of institutions of developing countries, facilitators and barriers along with numerous difficulties are found in establishing the nursing process.

Nursing process (NP) is a worldwide concept, which forms the base of nursing profession. It is a widely accepted scientific technique to direct excellent nursing care and procedures. It identifies, prevent and treat actual or potential health problems and promote wellness of clients. Implementation of nursing process in clinical settings 
facilitates high quality nursing care, improves client health outcomes and promotes nursing as a professional scientific discipline (Kamau, Maingi, Ndungu, \& Karonjo, 2016).

The use of the nursing process helps in making and planning a good, clear, and effective nursing care plan that is finally effective for improvement of the quality of patients' care. But despite the results obtained, some studies have shown that application of nursing process is facing numerous challenges. Few studies have been conducted to find the determinants of appropriate implementation of the nursing process (Zamanzadeh, Valizadeh, Tabrizi, Behshid, \& Lotfi, 2015).

Many hospitals face challenges with regards to nursing involvement, including scarcity of nursing resources, difficulty in engaging nurses at all levels from bed side to management, growing demands to participate in more, often duplicative, and quality improvement activates. Execution of the nursing process in medical situation not only facilitates high-quality nursing care but also improves client health outcomes during and after hospitalization. Moreover, it promotes nursing as a professional scientific discipline. It has been observed that execution of the nursing process enhance communication among nurses, provide a framework for assessing nursing interventions and enhanced customers' satisfaction with care. Failure to use nursing process leads to ineffective nursing care, low quality health care and conflicting roles (Akhtar, Hussain, Afzal, \& Gilani, 2018).

In practice, however, not all steps systematically implemented. During the last years, studies have been conducted in hospitals and health care institutions of many countries that revealed numerous difficulties in establishment of the nursing process (NP). Nevertheless, little known about the variables that are potentially associated with the use of the NP in health services. Advancing in knowledge on this process involves the exploration and analysis of variables related not only to the usage characteristics of the NP at institutions, but also to the characteristics of the institutional and nursing professionals' environment (Mahmoud \& Bayoumy, 2014).

A number of factors found that obstruct the effective application of nursing process. Some known problems in the practice of nursing care involve an inadequate information about the stages related with the nursing process, an unfair number of tasks assigned to nursing staff in accordance to their skills, the poor quality of compulsory professional education to carry out the task. Inadequate reports on the physical checkup associated to the illness, difficulty with describing diagnosis features are also included among these factors. In underdeveloped countries, Factors accompanying with failure to the implementation of the nursing process are classified into negative attitudes, incompetence, and lack of resources. (Akhtar et al., 2018).

Inadequate knowledge is a key barrier to the execution of nursing process in clinical settings. Barriers regarding the implementation of the nursing process in most healthcare organizations are related to nurse's observation and experience. Some of these obstacles are work assets and others associated to organization. Along with all the hurdles, there are some facilitators, which serve in the process of care. Quality patient care in health care facility settings depends on nurses' capacity to improve a comprehensive arrangement of care. Qualified nursing staff individuals who enhance their understanding of the nursing process and grow patient care arranging abilities has become a challenge for health care organizations. Implementation of the nursing process is concerned with the accessibility of the required number of professional and specialized staffs in the region according to the total number of patients admitted (Akhtar et al., 2018).

Significance of the Study:

The excellent performance of nurses during their clinical placement reveals the quality of patient care. Current study was a source of improving my knowledge regarding barriers and facilitators that influence the practice of nursing process. This study was also helpful for the management to make certain policies for implementation of nursing process in hospital setting.

Objectives of Study:

1. To determine the barriers in execution of nursing process among nurses of Mayo Hospital Lahore.

2. To determine the facilitators for execution of nursing process among nurses Mayo Hospital Lahore.

\section{Conceptual Definitions:}

Barriers:

A circumstance that keeps people or things apart or an obstacle which prevents communication or progress (Dictionary \& STREET, 1994).

\section{Facilitators:}

Someone who facilitates something that provides direct or indirect unobtrusive assistance and guidance to bring about an outcome such as learning, productivity, or communication (Merriam-Webster, 2006).

Execution:

The process of execution; carrying out of a plan, order, or course of action. (Dictionary \& STREET, 1994).

Operational Definition:

Barriers:

Barriers refers to those work or administration related factors that hinders the execution of nursing process in the surgical and medical wards of Mayo Hospital Lahore. 


\section{Facilitators:}

Role and performance of facilitators includes appropriate communication and having enough time to implement the nursing process easily in the surgical and medical wards of Mayo Hospital Lahore.

\section{Execution:}

Carrying out all steps of nursing process or putting all stages of nursing process into practice.

\section{Nursing process:}

It is an organized and systematic process which is composed of several steps; assessment, diagnosis, planning, interventions, application, and evaluation. This problem solving method is practiced by nurses to recognize, avoid and treat actual and potential health problems as well as to promote well-being.

\section{Variables:}

Independent variable:

Barriers in execution of nursing process. (Workload, tedious documentation) Facilitators in execution of nursing process. (Use books, availability of equipment).

Dependent variables:

Implementation of Nursing Process (NP Steps and NP Practice)

\section{LITERATURE REVIEW}

Based on the importance of nursing process, author confirm the researchers' point of view that the nursing process is an achievement full of interpretations that should be utilized by nurses in their clinical practice as a method for providing care, represents challenges in education and practice. The use of nursing process should be expanded in the hospital settings, according to which nurses working there, focuses on barriers and facilitators for the effective application of nursing process.

During the last three decades, many countries all over the world have been faced by increased demands of health care services. Internationally in Pakistan and Iran, like other countries, has flaws with the quality of health care provided by nurses. The nurses are expected to resolve their clients' health problems and make them able to face such health problems. It is also important to make them capable in advance. We can guarantee a reduction in mortality and morbidity by improving a better nursing care if we accept the fact that more capable nurses can provide better care and better understanding of patient's problems. Nursing process in surgical wards has not been considered as much as required the present study focuses on problems and facilitators which nurses face during implementation of their nursing process. (Farahani, Rastian, Rassouli, \& Sarbakhsh, 2016)

Nursing process is an international thought, which forms the base of nursing as profession. The nursing process is used in many hospitals for implementation of nursing care efforts (Momoh \& Chukwu, 2010). Execution of the nursing process in health care system provides better nursing care which subsequently improves patient's health outcomes during and after hospitalization and develop nursing as a scientific profession. Execution of the nursing process encourage nurse's communication skills, give chance to assess nursing interventions and increase patient's satisfaction with care roles whereas, negligence may lead to low-quality health care, the uselessness of the nursing care and conflicting roles among health care professionals (Wagoro \& Rakuom, 2015).

Many barriers effect the nursing process and obstruct the effective application of nursing process, some common barriers in the nursing care practice include lack of knowledge regarding nursing process, extra number of patients assigned to nursing staff as compared to their experience, allocation of different comprehensive tasks in accordance to their skills and lack of professional education that is essential to fulfill the task. Poor understanding of describing diagnosis features during physical examination of patients associated to the illness is also included in these factors (Hagos, Alemseged, Balcha, Berhe, \& Aregay, 2014).

Besides all the barriers, there are some facilitators too, which help to maintain quality care and evidence base practice in health care system. Health care system facilitates specialized nursing staff individually to develop their understanding of the nursing process and enhance the nurses' capacity to manage quality care which in return helps the nurses to improve quality care of patients and serves the health care institutions. Implementation of the nursing process is depend on the availability of the qualified staff in the area according to the total number of patients admitted (Zamanzadeh et al., 2015).

According to Agyeman and colleagues (2017) Nurses deliver up to $80 \%$ of all health care services; therefore, they are considered as the main part of healthcare system. The results of the study revealed that Novice nurses aged between 21 and 30 years were more likely to exercise nursing process $33(49.3 \%)$ as compared to nurses aged $31-40$ years $(24.1 \%), 41-40$ years $(8 \%)$ and $51-60$ years $(15.4 \%)$. New nurses with experience less than 5 years and experience 30 between 5 and 10 years were more likely to apply nursing process at $38.8 \%$ and $54.8 \%$, respectively compared to $11-15$ years (23.5\%) and 16 or more years (10.8\%) (Agyeman-Yeboah, Korsah, \& Okrah, 2017), uedes et al., 2012).

The results of another study showed more features, which helped in utilization and execution of nursing process. According to study results $96 \%$ nurses had adequate knowledge and practical experience regarding nursing process; $91 \%$ nurses educated and implemented it during the undergraduate study, and $90 \%$ nurses attend 
trainings regarding nursing process (Kelly et al., 2014).

Zaman Zadeh et al. (2015) initiated that $78.9 \%$ nurses told that hospital administration documented the nursing process as a structure for good nursing care delivery. Almost half $50 \%$ of nurse's reported that the hospital administration supports implementation of the nursing process, $75.4 \%$ nurses stated that the hospital administration should provide appropriate appliances to facilitate staff in the implementation of nursing process (Zamanzadeh et al., 2015).

A significant number of researchers approved the importance of opinion that the nurses should utilize nursing process in practice to attain better outcome related to patients in the health care system. The use of nursing process is based on the opinion of nurses working there in the hospital settings, assessment about barriers and facilitators for the implementation of nursing (Guedes, Turrini, Sousa, Baltar, \& Cruz, 2012).

During recent innovative world, nursing care achieved by using the nursing care process that is based on rational values. The nursing process is a careful perspective that help all skilled nurses to solve problems and deliver extremely high standards of care in health care system. The use of nursing process has modernized the nurse's procedures as nurses complete their tasks through nursing process easily and learn through speculated task (Kelly, Wicker, \& Gerkin, 2014).

A study has shown some failures in record the record of some steps of nursing process. According to the findings of study, although all steps of nursing process are not used. It was considered to use all steps of the nursing process as per specifically developed protocols. The implementation of these protocols will not only improve the use and registration of complete steps of nursing process but also help to redesign the formulary of data record with careful consideration of all steps and empower all members of nursing staff to implement the nursing process more efficiently. The study also identified that research should focus on accuracy of nursing documentation, factors which may cause difference in practice and errors in documentation quality and effects if these on nursing practice, patients' consequences and evaluation of total quality measurement.(Afolayan, Donald, Baldwin, Onasoga, \& Babafemi, 2013)

Nursing process is an up to dated technology of care that guides and supports the order of clinical rationals and it also enhances the quality of care. It integrates, organizes, and ensures the continuity of information, enables nursing staff to evaluate their efficiency and effectiveness and to reshape their performance according to patient's outcomes. (Barra, Dal Sasso, \& Baccin, 2014)

Nurses are the largest group of health care team all over the world. Nursing care totally depends upon the efficiency and effectiveness of health care system. Quality of nursing care is the main element for achieving quality health care services. Nursing process has an important role in quality of care but the implementation of is not well developed.(Semachew, 2018).

\section{RESEARCH METHODOLOGY}

This study was conducted to assess the barriers and facilitators for execution of nursing process among nurses of mayo hospital Lahore. A descriptive cross-sectional research design was used. Setting of the study was Mayo hospital Lahore. The study's target population were Nurses of Mayo Hospital Lahore. According to Solvin's formula, confidence coefficient was 95\% along with 5\% chances of error (Ellen, 2012). Sample size was 124 participants. In this study convenient sampling technique was used. Participants who had entire requirements and who were present at the time of data collection were included. A self-administered and structured questionnaire was adopted from the article "Barriers and Facilitators for Execution of Nursing Process among Nurses from Medical and Surgical Wards in a Public Hospital Lahore". Data collection plan is a major source to collect data. A self-administered questionnaire was used to collect data from the study participants and the participants had free hand to complete it and return it. Statistical Package for the social science (SPSS) 21 was used for data analysis.

\section{Including Criteria:}

1. Nurses age group between 21 to 35 years.

2. Have Job experience more than 2 years and maximum 25 years.

3. Those who are agree to participate.

4. Nurses from the surgical wards.

\section{Excluding Criteria:}

1. Nurses under the age group under 21 years and more than 35 years.

2. Job experience less than 2 years and more than 25 years.

3. Nurses who do not want to participate in study.

This study was taken approximately 5-6 months. Informed consent were obtained from all participants to participate in the study.

\section{Ethical Consideration:}

Investigator give all the necessary information regarding study to participants that help the participant to fill the consent form. The study was conducted in surgical wards of Mayo hospital Lahore. Study was conducted after taking permission letter from institutional review board committee of the Mayo Hospital Lahore. Rules 
were followed during study. A written consent was taken from the participants, respect given to all participants and all collected information was kept confidential. Rights were protected by the nursing code of ethics, which were as follows:

- Informed consent (attached in written form) was taken from all the participants.

- Entire information and data was kept confidential.

- Participants were remain anonymous throughout the study.

- The subjects were informed that there are no risks of the study.

- They were also informed that they will be free to withdraw at any time during the process of the study.

- Data was kept in under key and lock while keeping keys in hand. In laptop it was kept safe using password.

\section{RESULTS}

This Chapter includes the section of analysis. The focus of this chapter is to analyze the data, which was gathered through Self-Administered Questionnaire. Questionnaire contain four sections. First section consists of Demographic data of participants, then second is about Previous Experiences and Practices of the Nurses Regarding Nursing Process, third section include Barriers Encountered in Execution of the Nursing Process and then fourth and last section of questionnaire is Facilitators for Execution of Nursing Process. Descriptive analysis was used to analyze the data of questionnaire.

All performas were cross checked, record files were carefully prepared for entering data using SPSS version 21 for windows. Descriptive statistics like Frequency, Mean, Standard Deviation and variance were used to assess frequency and percentages of all questions. To avoid any bias, double entries were done in different computers. All the data was carefully analyzed. Data was analyzed through Statistical Package for the social science (SPSS) 21. The questionnaire's validity and reliability has already been measured by the author who gave permission to use the research instrument. Descriptive statistics was used to summarize the demographic data in the form of percentage and frequency.

Table No.1: Demographics characteristics:

\begin{tabular}{|l|l|l|l|}
\hline Variables & Groups & Percentage & Frequency \\
\hline \multirow{5}{*}{ Agender } & Male & $0.8 \%$ & 1 \\
\hline & Female & $99.2 \%$ & 123 \\
\hline & Total & $100 \%$ & 124 \\
\hline \multirow{5}{*}{ Qualification } & 21 to 25 years & $37.1 \%$ & 46 \\
\hline & 26 to 30 years & $46.8 \%$ & 58 \\
\hline & 31 to 35 years & $16.1 \%$ & 20 \\
\hline & Total & $100 \%$ & 124 \\
\hline \multirow{5}{*}{ Experience } & Nursing diploma & $66.1 \%$ & 82 \\
\hline & Post RN & $29.8 \%$ & 37 \\
\hline & BSN & $4.0 \%$ & 5 \\
\hline & Total & $100 \%$ & 124 \\
\hline & 2 to 5 Years & $46.0 \%$ & 57 \\
\hline & 6 to 9 years & $25.8 \%$ & 32 \\
\hline & 10 to 13 years & $18.5 \%$ & 23 \\
\hline & 14 to 17 years & $8.9 \%$ & 11 \\
\hline & 18 to 21 years & $.8 \%$ & 1 \\
\hline & Total & $100 \%$ & 124 \\
\hline
\end{tabular}

In this study the total participants were $\mathrm{n}=124$, in which $0.8 \%$ of the participants were male and $99.2 \%$ participants were female. $37.1 \%$ participants from total were aged between $21-25$ years, $46.8 \%$ participants fall in age group between $26-30$ years and $16.1 \%$ participants were between the age group of 31-35 years. Participants included in study were holding degree and diploma and some were having both. 66.1\%participants had nursing diploma, 29.8\% participants had Post RN degree and 5 participants had BSN degree. In this study mostly candidates fall in age group between 21-30 years so they were not too much experienced. $46 \%$ participants had 25 years' experience, $25.8 \%$ participants had 6-9 years' experience, $18.5 \%$ participants had 10-13 years' experience, $8.9 \%$ participants had experience between 14-17 years and 8\% participants had experience between 18-21 years. 


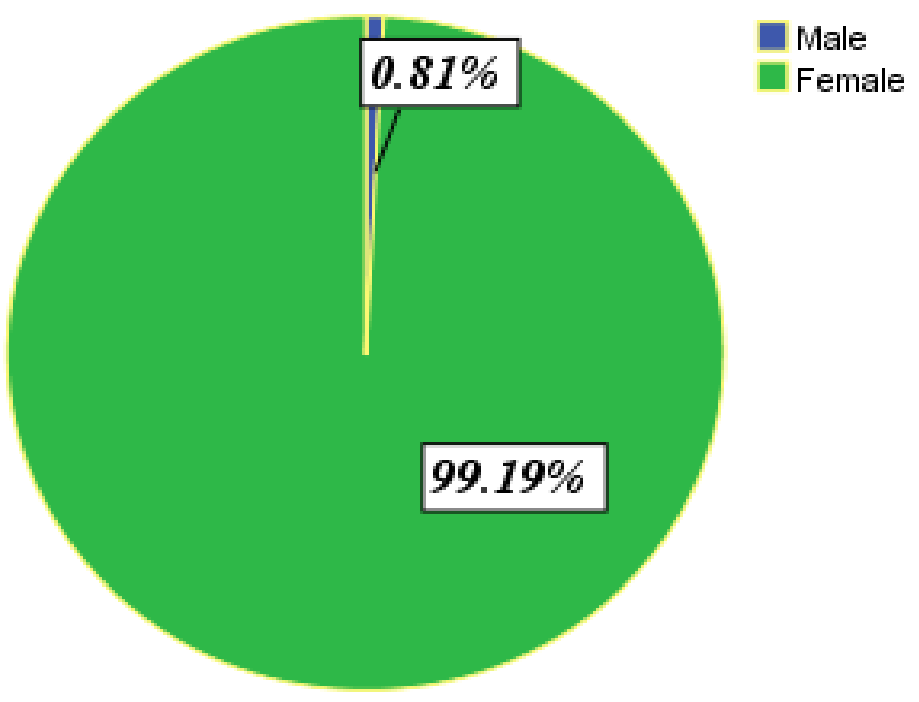

FIGURE 1 GENDER OF STUDY PARTICIPANTS

$\square 21-25$

26-30

$\square 31-35$

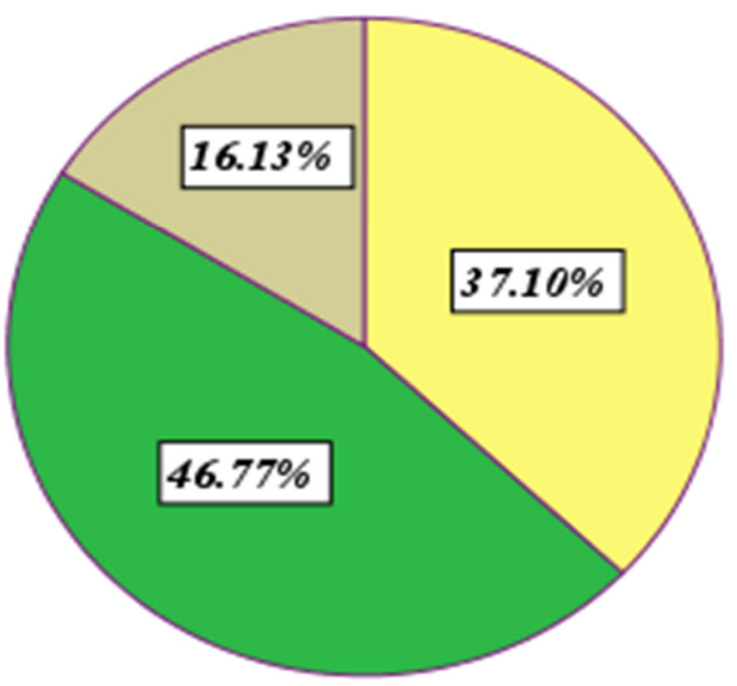

FIGURE 2 AGE OF STUDY PARTICIPANTS 


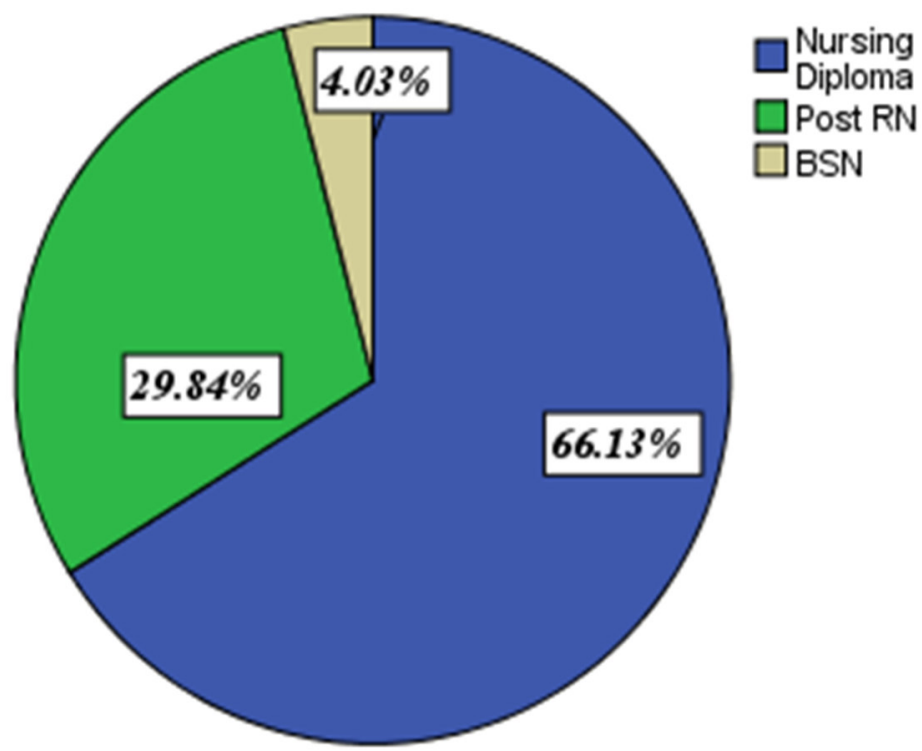

FIGURE 3 QUALIFICATION OF STUDY PARTICIPANTS

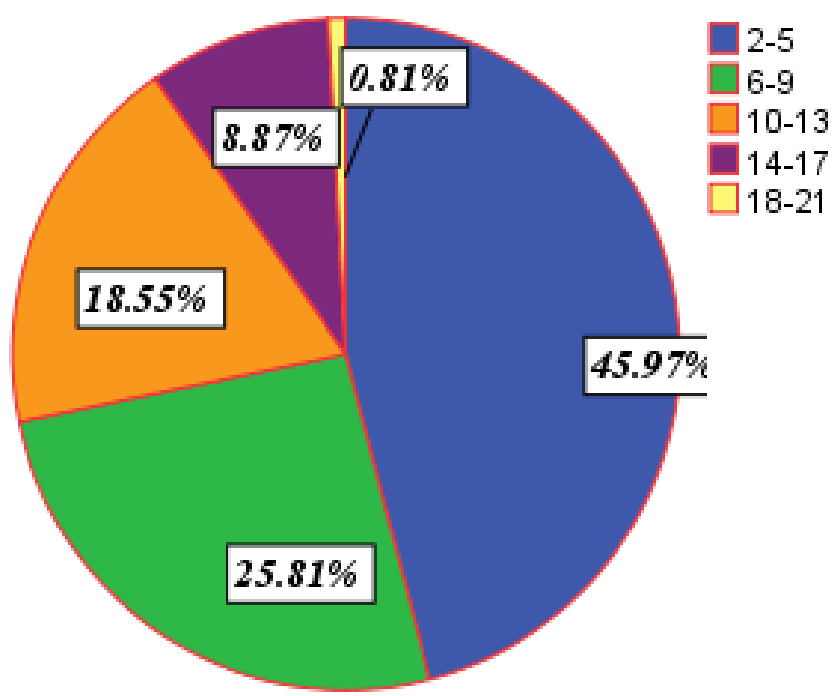

FIGURE 4 EXPERIENCE OF STUDY PARTICIPANTS

Descriptive analysis of Independent Variables:

Knowledge:

Total scores of knowledge were used to calculate means, median, range and standard deviation with the purpose of conducting descriptive analysis of knowledge. $100 \%$ participants were used for analysis purpose mean was 4.3 , median was 4.25, standard deviation was 0.65 and variance was 0.42 and the range was 3 .

\section{Confidence:}

Total scores confidence were used to calculate means, median, range and standard deviation with the purpose of conducting descriptive analysis

Of confidence. $100 \%$ participants were used for analysis purpose mean was 3.36 , median was 3.50 , standard deviation was 0.64 and variance was 0.41 and the range was 3 .

\section{Acceptability:}

Total scores of acceptability were used to calculate means, median, range and standard deviation with the purpose of conducting descriptive analysis

Of knowledge. $100 \%$ participants were used for analysis purpose mean was 2.9 , median was 3 , standard deviation was 0.59 and variance was 0.35 and the range was 3 .

\section{Barriers:}

Total scores of barriers were used to calculate means, median, range and standard deviation with the purpose of conducting descriptive analysis

Of knowledge. $100 \%$ participants were used for analysis purpose mean was 3.32 , median was 3.36 , standard deviation was 0.38 and variance was 0.51 and the range was 3 . 


\section{Facilitators:}

Total scores of facilitators were used to calculate means, median, range and standard deviation with the purpose of conducting descriptive analysis

Of knowledge. $100 \%$ participants were used for analysis purpose mean was 3.56 , median was 3.71 , standard deviation was 0.48 and variance was 0.32 and the range was 3 .

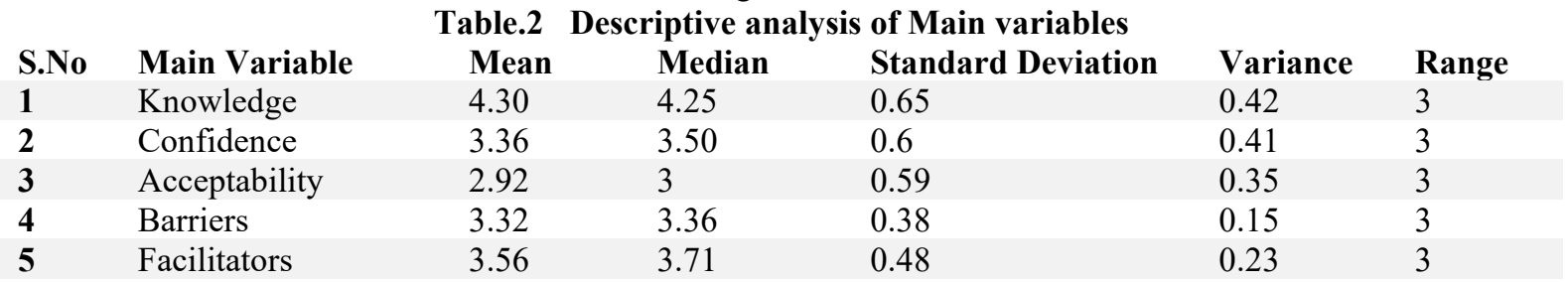

Validity and Reliability Assessment:

Reliability Testing:

Presents Cronbach's alpha, a scale been used in this study for measuring reliability of the research instrument and it is most often used measurement scale.

\begin{tabular}{ll}
\hline No. of items & 30 \\
\hline Cronbach's alpha & .713
\end{tabular}

Cronbach's alpha above 0.70 is considered to be the acceptable indicator of internal consistency reliability. The alpha value of items is .713 which is in acceptable range which shows that the instrument used for collecting data in this study were reliable

\section{Validity Testing:}

Validity was tested on overall items of tool except demographics and it was tested through factor analysis, no item was dropped and the no. of items was 30. Normal acceptable criteria for KMO value must be above .60 and Bartlett's test must be significant. According to this criteria study's validity measurement was in normal and acceptable range as given below.

\begin{tabular}{lllll}
\hline \multirow{2}{*}{ No. of items } & KMO & \multicolumn{2}{l}{ Bartlett's Test } & \\
\cline { 3 - 5 } & & Approx. & Df & significance \\
\hline 30 & .697 & 2012.003 & 435 & $.000^{* * *}$ \\
\hline
\end{tabular}

After demographics, second step of my tool were some variables, analysis of which have been done through Likert 5 scale ratings tool which are strongly disagree(SD), disagree(D), not sure(N), agree $(\mathbf{A})$ and strongly agree(SA). Second portion of my questionnaire (Previous Experiences and Practices of the Nurses Regarding Nursing Process (NP) further falls into three categories. First category of second portion is "Nurses views about their Nursing Process knowledge" and its results are shown in the following table. (Table.No.1).

\section{TABLE 1}

\begin{tabular}{l|l|l|l|l|l|l|l}
\hline S.No & Question & Total & SD & D & N & A & SA \\
\hline 1 & I have good knowledge in Nursing process. & 100 & 2.4 & 3.2 & 4.8 & 28.8 & 61.3 \\
\hline 2 & Got knowledge from training College. & 100 & 1.6 & 1.6 & 4 & 41.1 & 51.6 \\
\hline 3 & I get knowledge from seminars/workshops. & 100 & 4.8 & 7.3 & 7.3 & 37.9 & 42.7 \\
\hline 4 & I need more information/tutorials to practice nursing process. & 100 & .8 & 0 & 8.9 & 47.6 & 42.7 \\
\hline
\end{tabular}




\section{Research Questions:}

\section{Q.No.1.1: I have good knowledge in nursing process?}

Figure 1.1 reveals that $61.2 \%$ participants were strongly agree about having good knowledge in nursing process, $28.2 \%$ participants were only agree, $4.8 \%$ participants were not sure about this question, $3.2 \%$ participants were disagree this and $2.4 \%$ participants were totally strongly disagree about having good knowledge in nursing process.

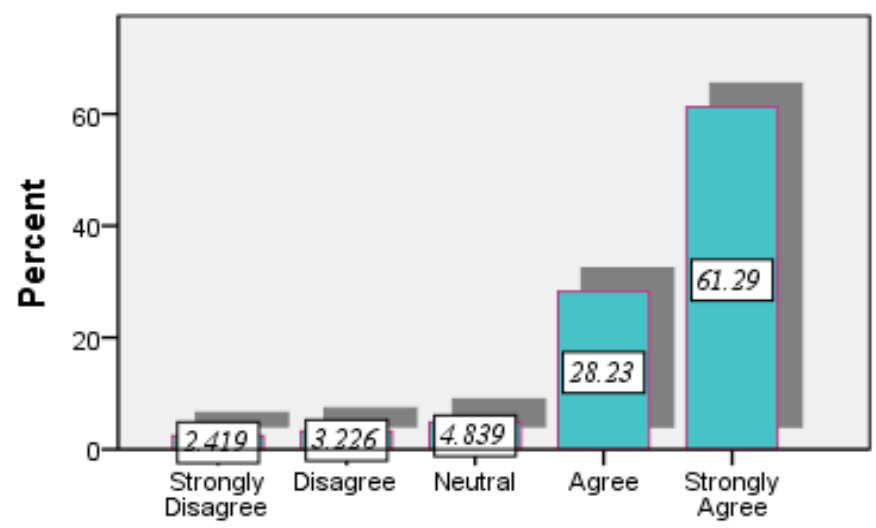

FIGURE 1.1

Q.No.1.2: I got knowledge from training college?

Figure 1.2 shows that $51.6 \%$ participants are strongly agreed about getting knowledge from training college, $41.1 \%$ participants are agreed, $4.0 \%$ participants are not sure, $1.6 \%$ participants are disagreed and $1.6 \%$ participants are strongly agreed about getting knowledge from training college.

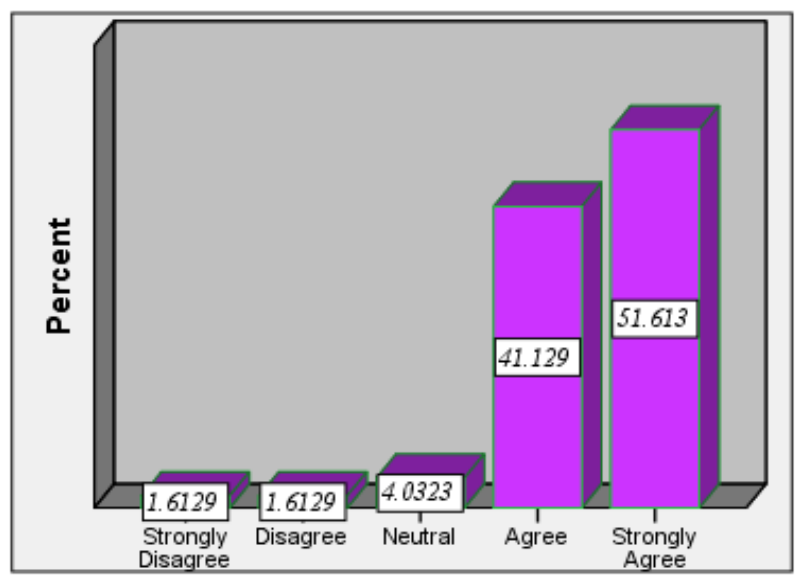

FIGURE.1.2

Q.No.1.3: I got knowledge from seminars/workshops?

Figure 1.3 that $42.7 \%$ participants were strongly agree about getting knowledge from seminars or workshops, $37.9 \%$ were agree, $7.2 \%$ were not sure, $7.2 \%$ were disagree and $4.8 \%$ participants were strongly disagree about getting knowledge from seminars and workshops.

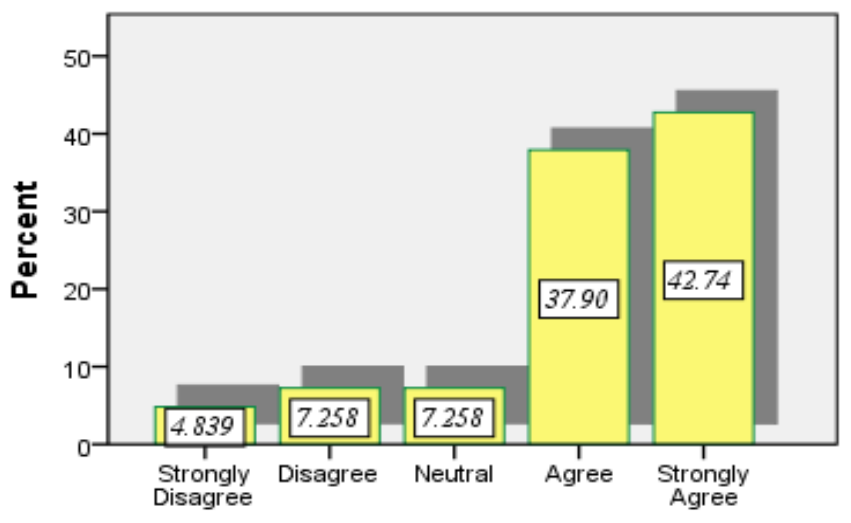

FIGURE.1.3 
Q.No.1.4: I need more information/tutorials to practice the Nursing process?

Figure 1.4 shows that $42.7 \%$ participants were strongly agree about need of more information and tutorials to practice nursing process, $47.5 \%$ were agreed, $8.8 \%$ were neutral and $0.8 \%$ participants were not having any need about more information on practice of nursing process.

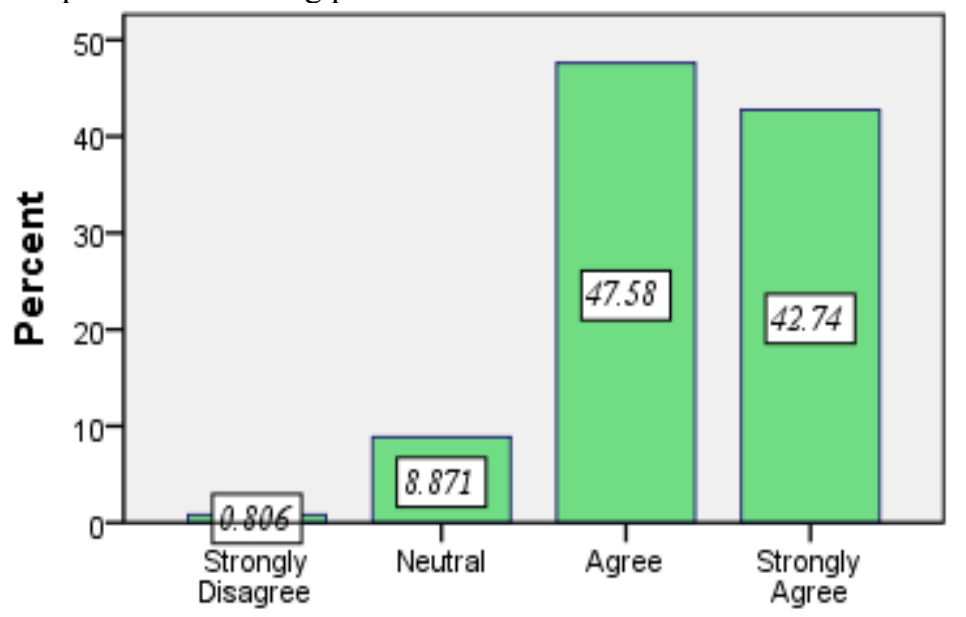

FIGURE 1.4

From section 2, second category is "Perceived confidence in application of nursing process" and its results are shown in following table.

TABLE 2

\begin{tabular}{l|l|l|l|l|l|l|l} 
S.No & Question & Total & SD & D & N & A & SA \\
\hline 1 & I am able to apply Nursing process correctly & 100 & 0.8 & 4.0 & 10.5 & 58.9 & 25.8 \\
\hline 2 & $\begin{array}{l}\text { I understand Nursing process well but found it difficult to } \\
\text { implement. }\end{array}$ & 100 & 5.6 & 11.3 & 13.7 & 46.8 & 22.6 \\
\hline 3 & I found it confusing & 100 & 29.0 & 29.8 & 22.6 & 16.1 & 2.4
\end{tabular}

Q.No.2.1: I am able to apply Nursing process correctly.

Figure 2.1 portrays that $25.81 \%$ participants were strongly agree about being able to perform nursing process correctly, $58.9 \%$ were agree, $10.9 \%$ were not sure, $4 \%$ were disagree and $0.8 \%$ were strongly disagree about being able to perform nursing process correctly.

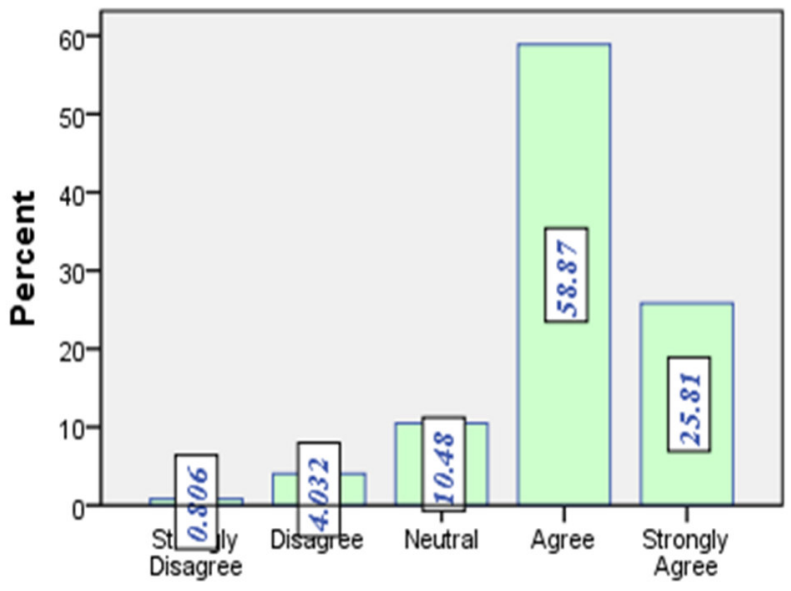

Figure 2.1 
Q.No.2.2: I understand Nursing process well but found it difficult to implement.

Figure 2.2 shows that $22.5 \%$ of participants fall in category of strongly angry that they understand nursing process but they found it difficult to implement, $46.7 \%$ were only agree, $13.7 \%$ were not sure, $11.2 \%$ were disagree and $5.6 \%$ were strongly disagree about this statement.

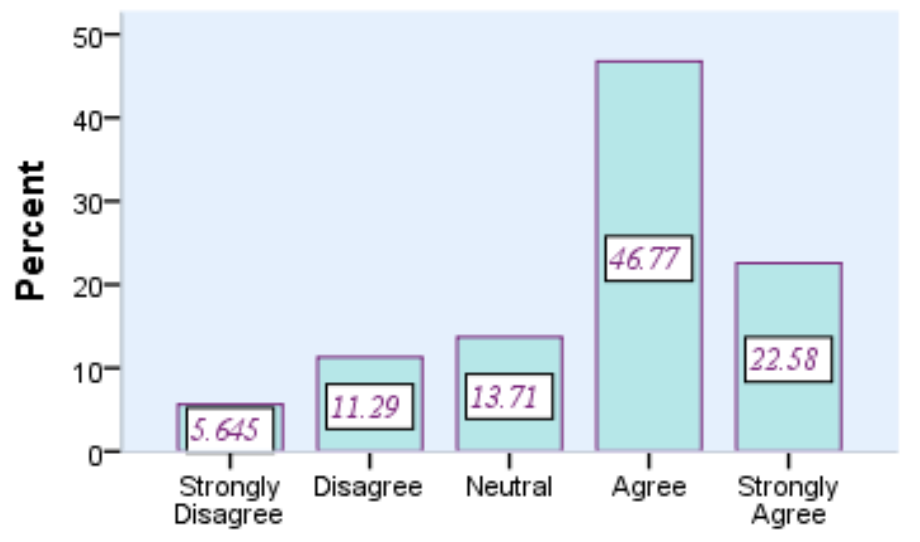

\section{Q.No.2.3: I found it confusing.}

FIGURE 2.2

In figure 2.3 , about $2.4 \%$ participants found it confusing and fall in category of strongly agree, $16.1 \%$ were agree, $22.5 \%$ were not sure either it was confusing or not, $29.8 \%$ were disagree to this statement and $29 \%$ were participants strongly disagree this statement.

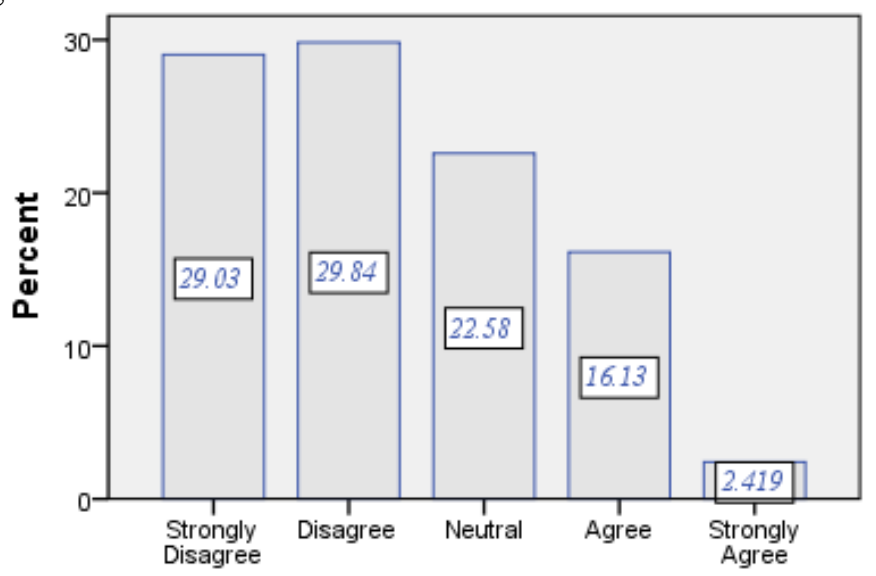

FIGURE 2.3

From portion 2, third category is "Acceptability and willingness to practice the nursing process by nurses" which has 5 questions and its results are in following table.

TABLE 3

\begin{tabular}{l|l|l|l|l|l|l|l} 
S.No & Question & Total & SD & D & N & A & SA \\
\hline 1 & I am agreed to apply Nursing process in patients' care & 100 & 1.6 & 0 & 8.1 & 38.7 & 51.6 \\
\hline 2 & I will prefer to be left out of this Nursing process practice. & 100 & 48.4 & 24.2 & 12.1 & 12.1 & 3.2 \\
\hline 3 & I practice the nursing process very often. & 100 & 2.4 & 12.9 & 16.9 & 34.7 & 33.1 \\
\hline 4 & I have never practiced nursing process before. & 100 & 56.5 & 21.8 & 7.3 & 12.1 & 2.4 \\
\hline 5 & $\begin{array}{l}\text { Higher nursing degrees should leave the application of } \\
\text { nursing process. }\end{array}$ & 100 & 26.6 & 16.9 & 34.7 & 16.1 & 5.6
\end{tabular}


Q.No.3.1: I am agreed to apply Nursing process in patients' care.

Figure 3.1 shows that $51.6 \%$ participants were strongly agree to apply nursing process in patients care, $38.7 \%$ agree, $8 \%$ were neutral and $1.6 \%$ participants strongly disagree to implement it during patients care.

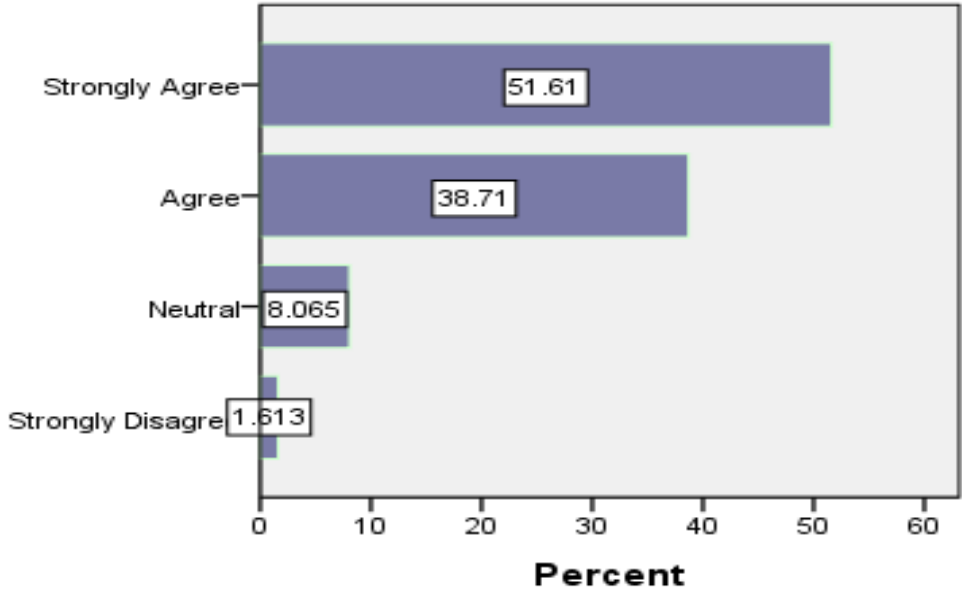

FIGURE 3.1

Q.No.3.2: I will prefer to be left out of this Nursing process practice.

Figure 3.2 reveals that $3.2 \%$ participants were strongly agree to left nursing process practice, $12.1 \%$ were agree, $12.1 \%$ were neutral, $24.1 \%$ were disagree and $48.3 \%$ participants strongly disagree to left its practice.

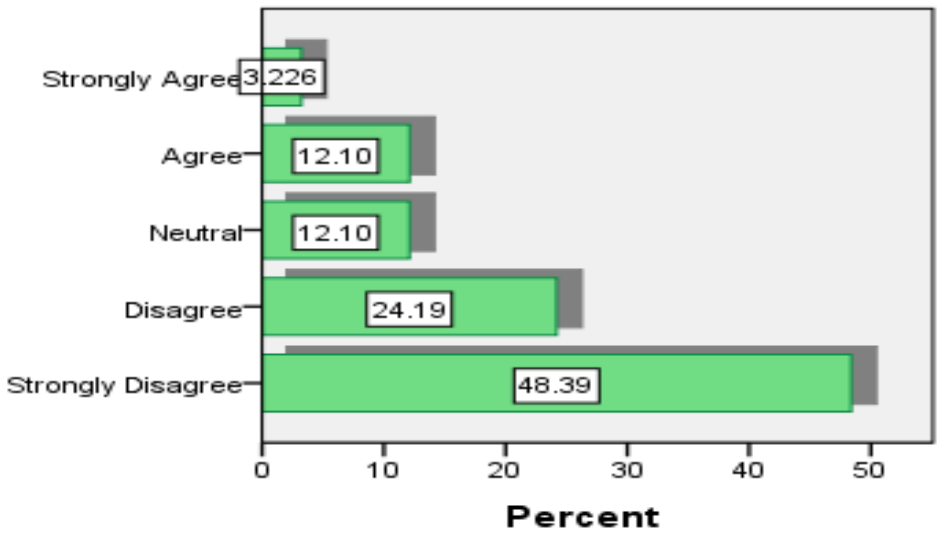

FIGURE 3.2

Q.No.3.3: I practice the nursing process very often.

Figure 3.3 shows that $33 \%$ participants were strongly agree that they practice it often, $34.6 \%$ were agree, $16.9 \%$ were not sure about their practice of nursing process, $12.9 \%$ were disagree and $2.4 \%$ were strongly disagree about this statement of practicing it often.

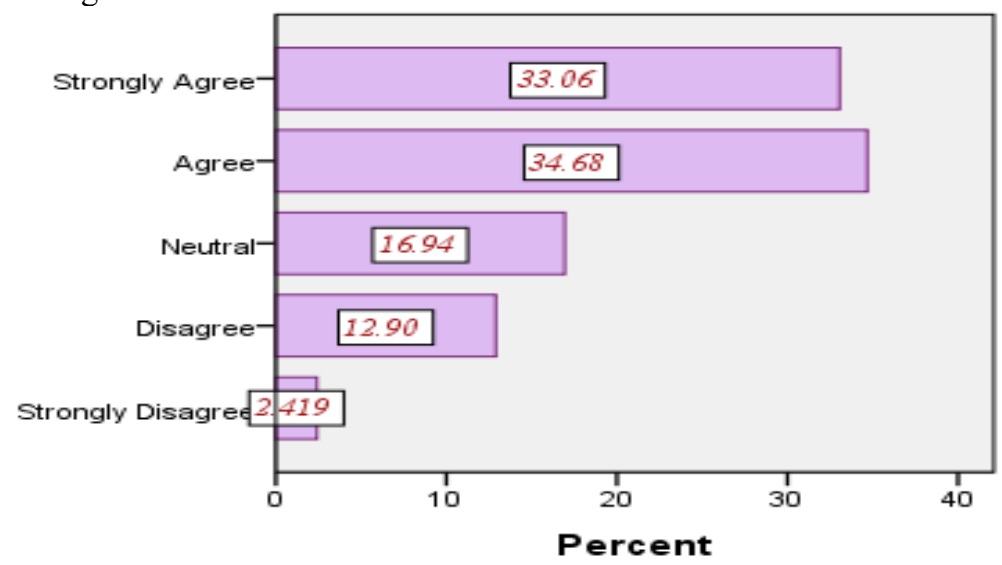

FIGURE 3.3 
Q.No.3.4. I have never practiced the nursing process before.

Figure 3.4 evidences that $2.4 \%$ participants were strongly agree that they have never practiced nursing process, $12.1 \%$ were agree, $7.2 \%$ were neutral, $21.8 \%$ were disagree and $56.4 \%$ participants were strongly disagree that they haven't practiced it ever.

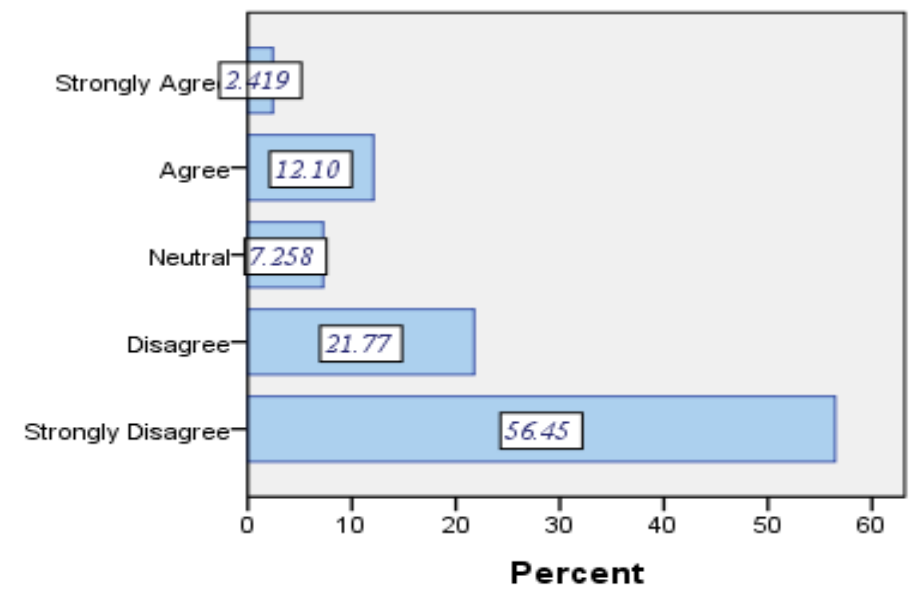

FIGURE 3.4

Q.No.3.5. Higher nursing degrees should leave the application of nursing process.

Figure 3.5 is showing that $5.6 \%$ participants were strongly agree about statement to left nursing process for higher degrees, $26.1 \%$ were agreed, $34.6 \%$ were not sure about it, $16.9 \%$ were disagree and $26.6 \%$ were strongly disagreed to left it for higher degrees.

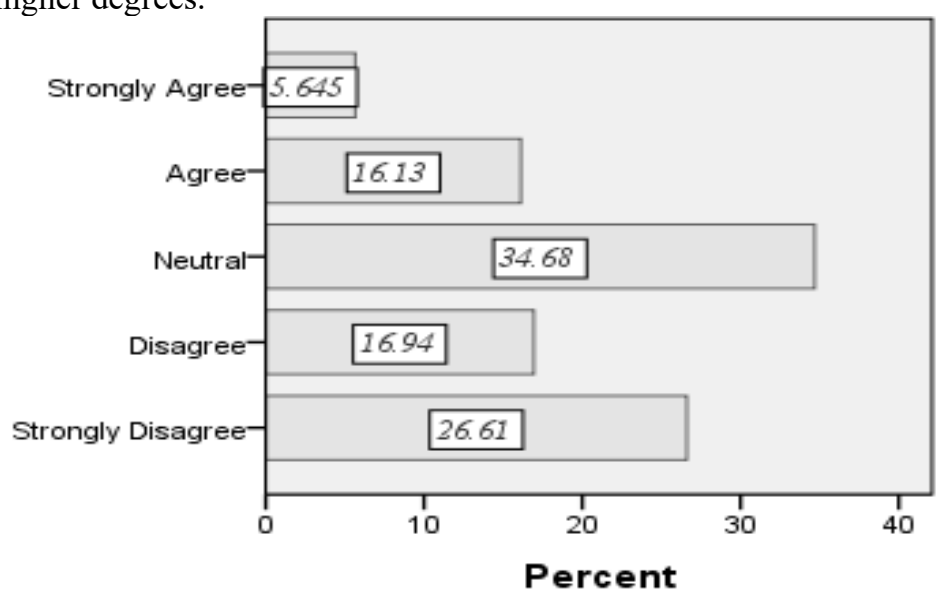

FIGURE 3.5

Third section of this tool was "Barriers Encountered in Execution of the Nursing Process. Its results are in following table.

TABLE 4

\begin{tabular}{l|l|l|l|l|l|l|l} 
S.No & Question & Total & SD & D & N & A & SA \\
\hline 1 & $\begin{array}{l}\text { Hospital management needs to be enlightened on its } \\
\text { benefits }\end{array}$ & 100 & 0 & 3.2 & 12.1 & 78.2 & 6.5 \\
\hline 2 & $\begin{array}{l}\text { There is not sufficient equipment for the implementation of } \\
\text { nursing process. }\end{array}$ & 100 & 0 & 5.6 & 6.5 & 73.4 & 14.5 \\
\hline 3 & $\begin{array}{l}\text { The nursing staff and patient ratio is not adequate to fully } \\
\text { practice the nursing process (Workload) }\end{array}$ & 100 & 0 & 4.8 & 6.5 & 44.4 & 44.4 \\
\hline 4 & A nurse cannot see any purpose for writing the care plan. & 100 & 40.3 & 22.6 & 14.5 & 20.2 & 2.6 \\
\hline 5 & Not being able to follow patients & 100 & 43.5 & 29.0 & 14.5 & 11.3 & 1.6 \\
\hline 6 & Staff had no experience in nursing process & 100 & 60.5 & 17.7 & 6.5 & 12.9 & 2.4 \\
\hline 7 & Nursing process is time consuming & 100 & 8.1 & 12.9 & 13.7 & 60.5 & 4.8 \\
\hline 8 & Nursing process requires tedious (too long) documentation & 100 & 4.0 & 11.3 & 29.0 & 46.0 & 9.7 \\
\hline 9 & Barriers related to resources & 100 & 0.8 & 7.3 & 17.7 & 54.0 & 20.2 \\
\hline 10 & Barriers related to administration & 100 & 0 & 3.2 & 17.7 & 54.0 & 25.0 \\
\hline 11 & Barriers related to nursing process & 100 & 3.2 & 8.1 & 16.1 & 63.7 & 8.9
\end{tabular}


Q.No.4.1: Hospital management needs to be enlightened on its benefits.

In Figure 4.1, about 3.2\% participants were disagree about a hospital management need to enlighten its benefits, $12.1 \%$ were not sure about this statements, $78.2 \%$ were agree and $6.4 \%$ participants were strongly agree that hospital management should enlighten its benefits.

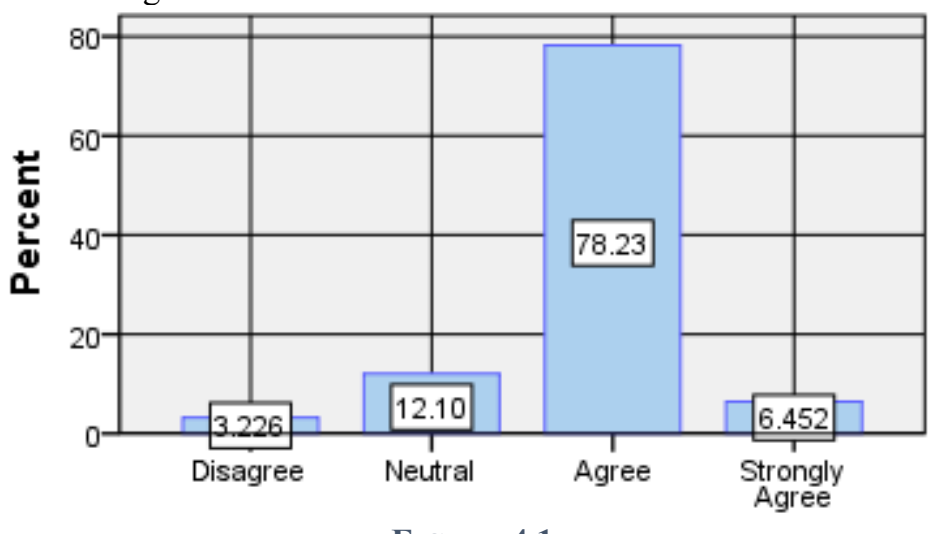

FIGURE 4.1

Q.No.4.2: There is not sufficient equipment for the implementation of nursing process.

Figure 4.2 reveals that 5.6\% participants didn't thinks so that there is insufficient equipment for implementation of nursing process, $6.4 \%$ were not sure, $73.3 \%$ were agree and $14.5 \%$ were strongly agree that there is insufficient equipment for implementation of process.

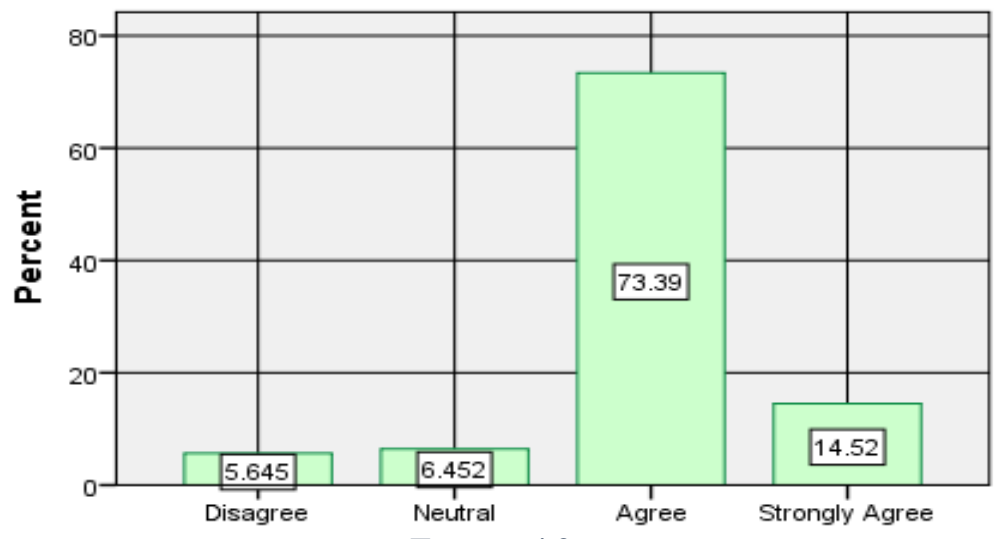

Q.No.4.3: The nursing staff and patient ratio is not adequate to fully practice the nursing process (Workload).

Figure 4.3 portrays that participants $4.8 \%$ were disagree about statement that nursing staff strength ratio is inadequate to fully practice nursing process, $6.4 \%$ were neutral, $44.3 \%$ were agree and $44.3 \%$ were strongly agree.

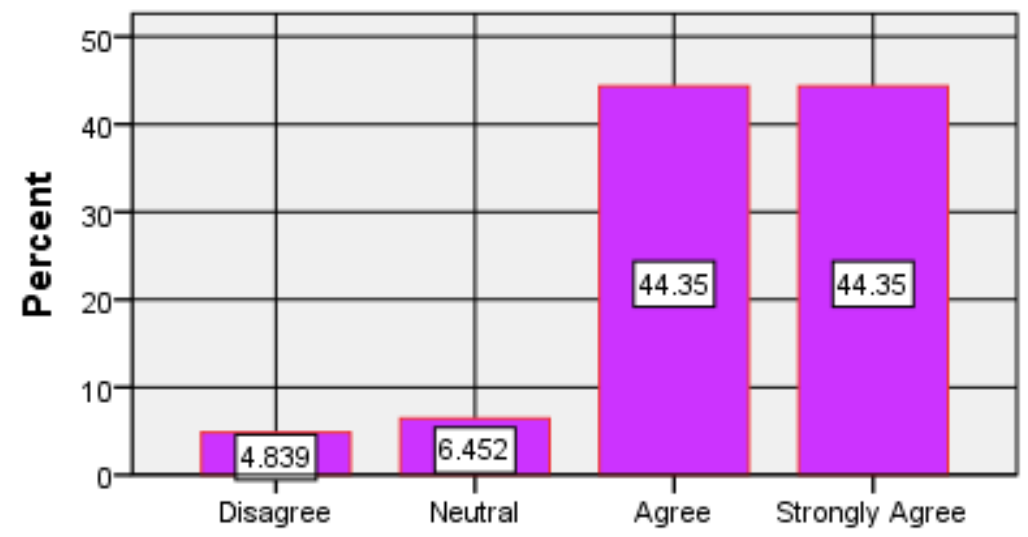

FIGURE 4.3 
Q.No.4.4: A nurse cannot see any purpose for writing the care plan.

Figure 4.4 shows that $40.3 \%$ participants were strongly disagree about this statement that a nurse can't see any purpose for writing care plan, $23 \%$ were disagreed, $14.5 \%$ were neutral, $20.1 \%$ were agreed and $2.1 \%$ were strongly agreed at this statement.

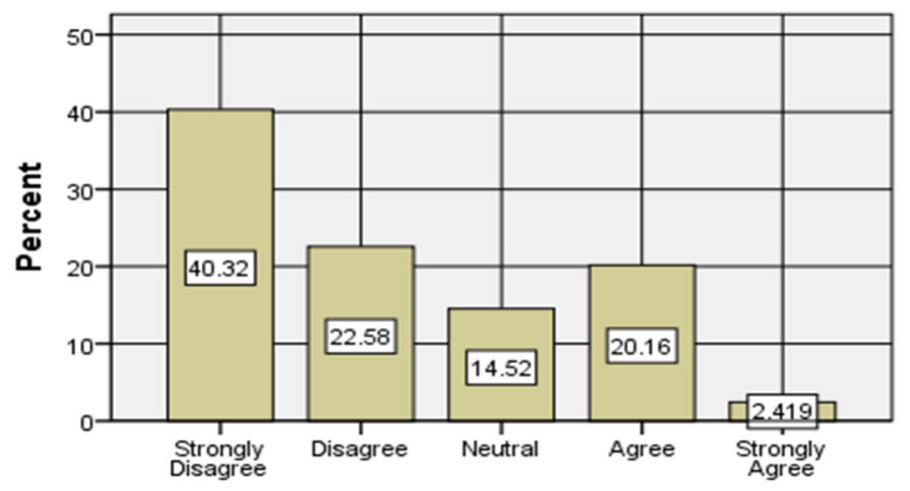

FIGURE 4.4

Q.No.4.5: Not being able to follow patients.

Figure 4.5 evidences that $43.5 \%$ were strongly disagreed about not being able to follow patients, $29 \%$ were disagreed, $14.5 \%$ were not sure, $11.2 \%$ were agree and $1.6 \%$ were strongly agree about this statements of participants.

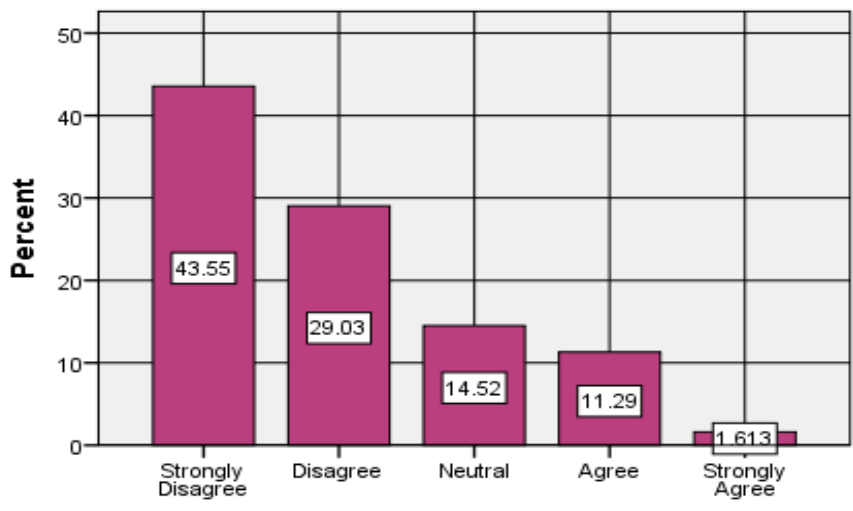

FIGURE 4.5

Q.No.4.6: Staff had no experience in nursing process.

Figure 4.6 reveals that $60.4 \%$ participants strongly deny the statement that nurses had no nursing process information, $17.7 \%$ were disagree, $6.4 \%$ were neutral, $13 \%$ were agree and $2.4 \%$ were strongly agree about this statement.

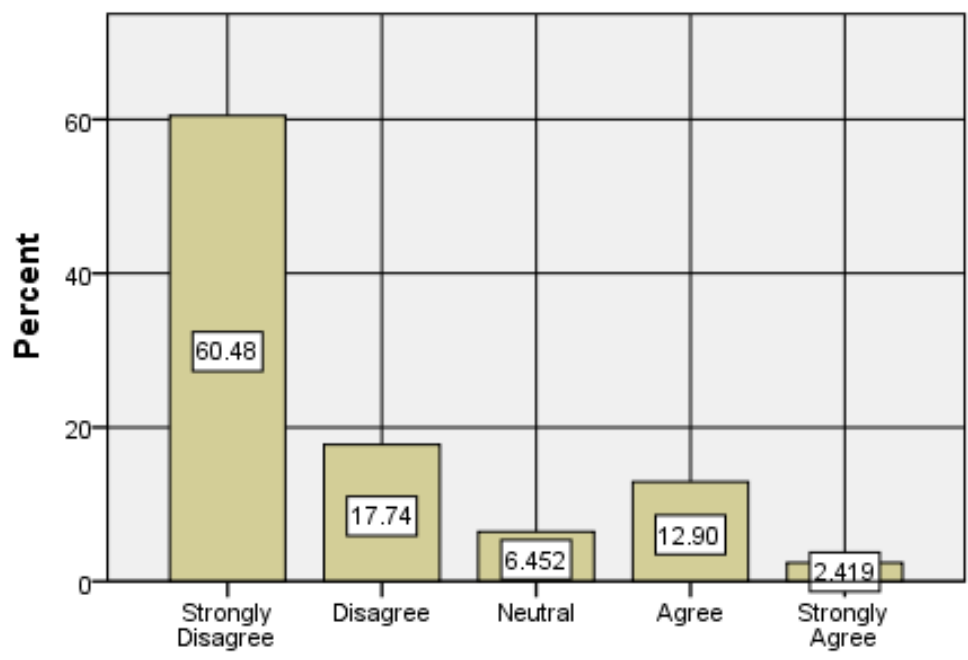

FIGURE 4.6 
Q.No.4.7: Nursing process is time consuming.

Figure 4.7 portrays that $8 \%$ were strongly disagree, $13 \%$ were disagree, $13.7 \%$ were neutral, $60.4 \%$ were agree and $4.8 \%$ were strongly agreed that nursing process is time consuming.

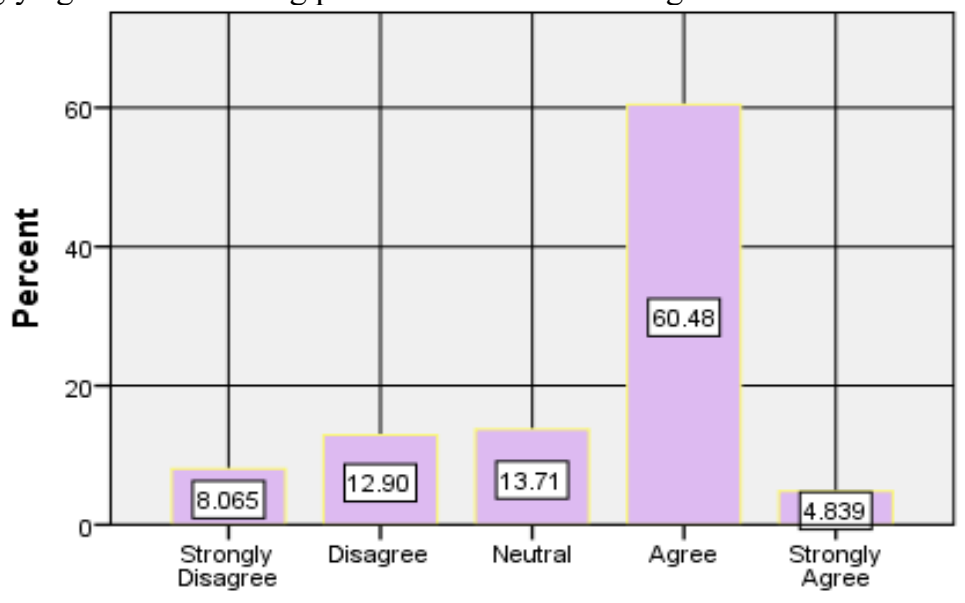

FIGURE 4.7

Q.No.4.8: Nursing process requires tedious (too long) documentation.

Figure 4.8 reveals that $4 \%$ participants were strongly disagree, $11.2 \%$ were disagree, $29.0 \%$ were neutral, $46 \%$ were agree and $9.6 \%$ were strongly agree that it requires tedious documents.

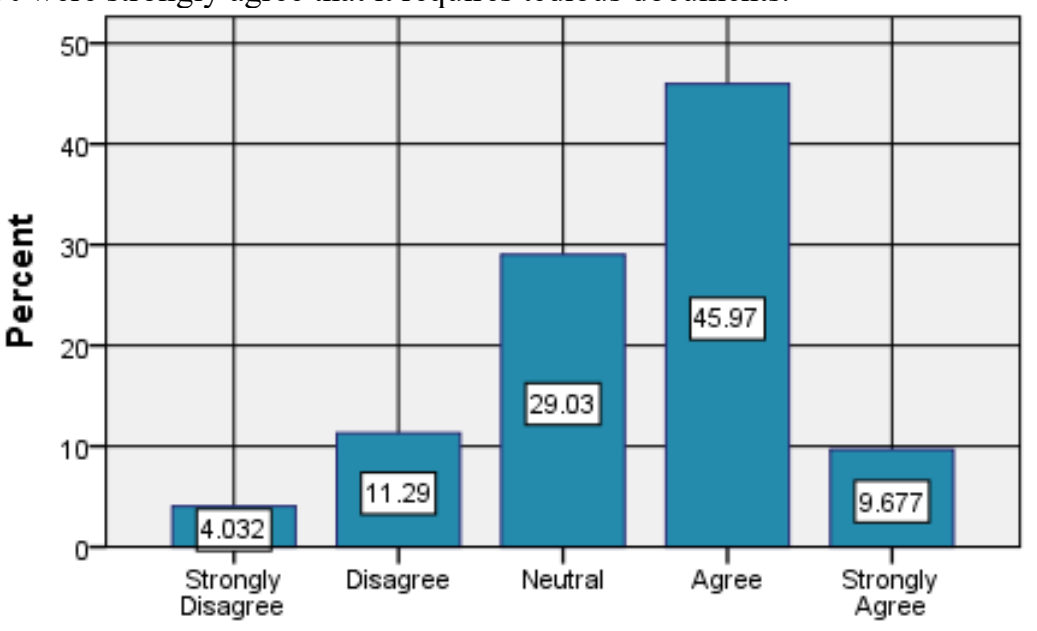

FIGURE 4.8

Q.No.4.9: Barriers related to resources.

Figure 4.9 shows that $0.8 \%$ participants strongly deny that there were barriers related to resources, $7.2 \%$ were disagree, $17.7 \%$ were not sure, $54 \%$ were agree and $20.1 \%$ were strongly agree.

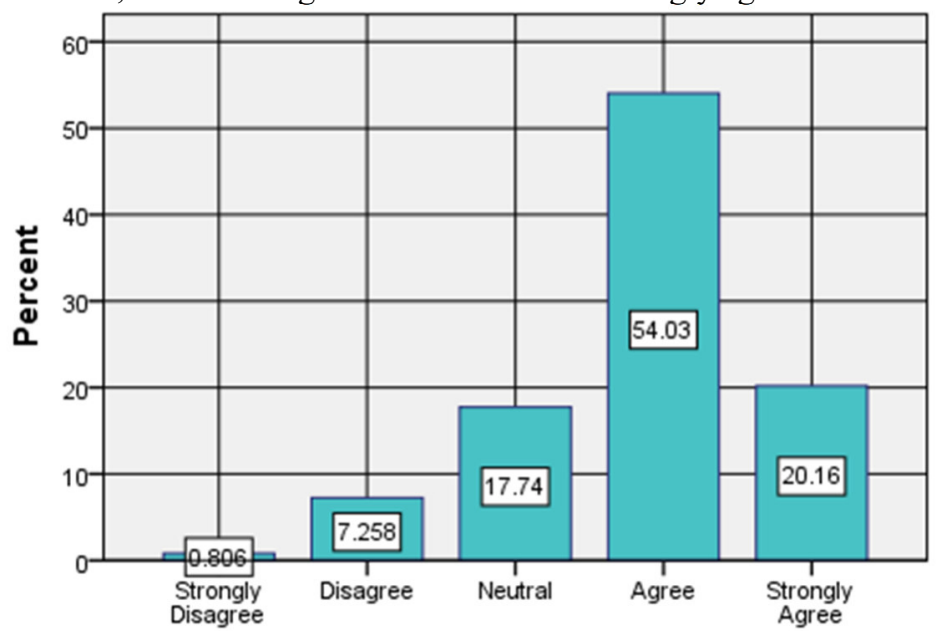

FigURE 4.9 
Q.No4.10: Barriers related to administration.

Figure 4.10 evidences that $3.2 \%$ participants deny the statement that were barriers related to administration, $17.7 \%$ were not sure, $54 \%$ were agreed and $25 \%$ were strongly agree.

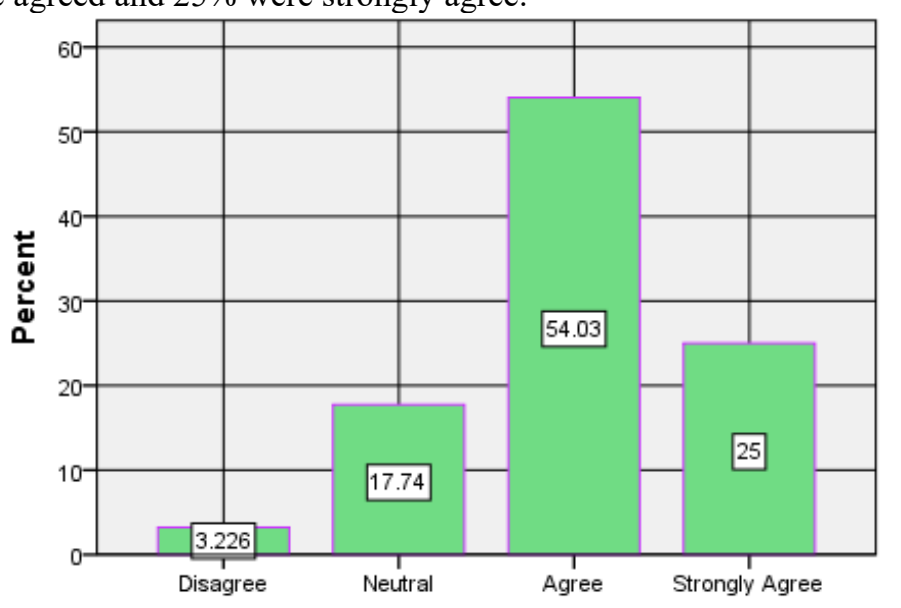

FigURE 4.10

Q.No.4.11: Barriers related to nursing process.

Figure 4.11 reveals that the statement " barriers related to nursing process was strongly denied by $3.2 \%$, denied by $8 \%$, not sured by $16.1 \%$, agreed by $63.7 \%$ and strongly agreed by $8.8 \%$.

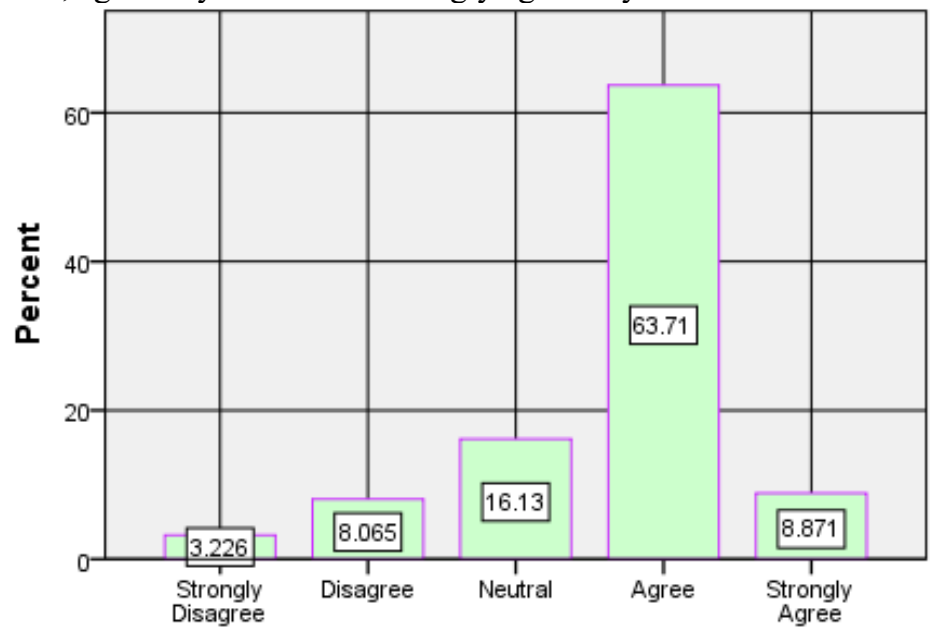

FIGURE 4.11

The last portion of my data analysis is "Facilitators for Execution of Nursing Process" and its results are shown in table below.

TABLE 5

\begin{tabular}{l|l|l|l|l|l|l|l} 
S.No & Question & Total & SD & D & N & A & SA \\
\hline 1 & Had adequate brochures in the unit & 100 & 2.4 & 28.2 & 49.2 & 11.3 & 8.9 \\
\hline 2 & Had enough time for performing the phase & 100 & 8.1 & 54.8 & 17.7 & 12.9 & 6.5 \\
\hline 3 & Used books as reference sources & 100 & 3.2 & 17.7 & 26.6 & 46.8 & 5.6 \\
\hline 4 & Found it easy to communicate & 100 & 1.6 & 8.9 & 25.0 & 53.2 & 11.3 \\
\hline 5 & Learned and executed it during undergraduate study & 100 & 1.6 & 3.2 & 15.3 & 55.6 & 24.2 \\
\hline 6 & Received theoretical-practical training in the hospital & 100 & 0.8 & 4.8 & 9.7 & 41.1 & 43.5 \\
\hline 7 & Had the theoretical knowledge and practical experience & 100 & 0.8 & 1.6 & 15.3 & 34.7 & 47.6
\end{tabular}


Q.No.5.1: Had adequate brochures in the unit.

Figure 5.1 is showing that the statement "had adequate brouchers in unit" was strongly disagreed by $2.4 \%$, agreed by $28.2 \%$, not sured by $49.1 \%$, agreed by $11.2 \%$ and strongly agreed by $8.8 \%$ participants.

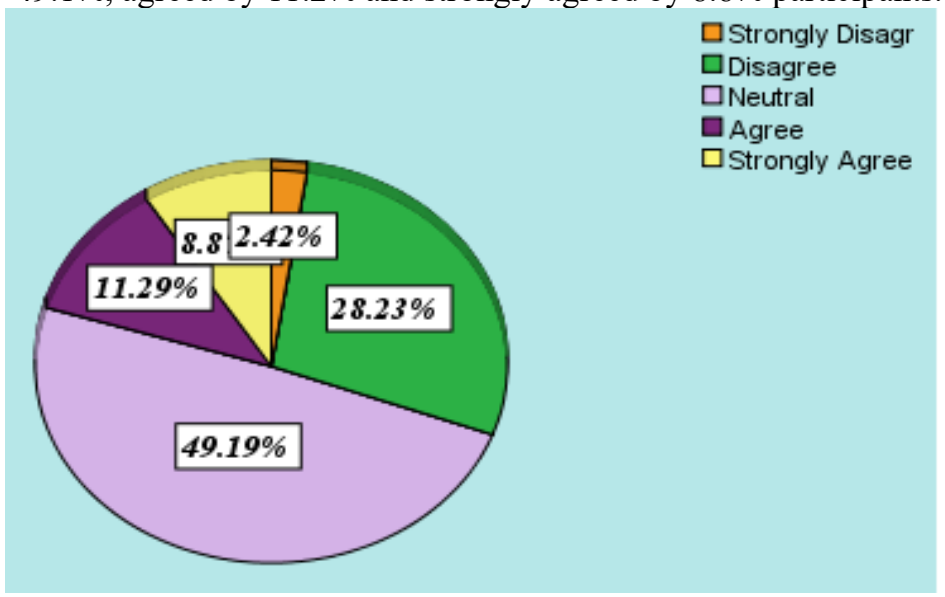

FIGURE 5.1

Q.No.5.2: Had enough time for performing the phase.

Figure 5.2 shows that $8 \%$ participants were strongly disagreed at having enough time for performing phase, $54.8 \%$ disagreed, $17.7 \%$ were not sure, $12.9 \%$ were agree and $6.4 \%$ were strongly agree.

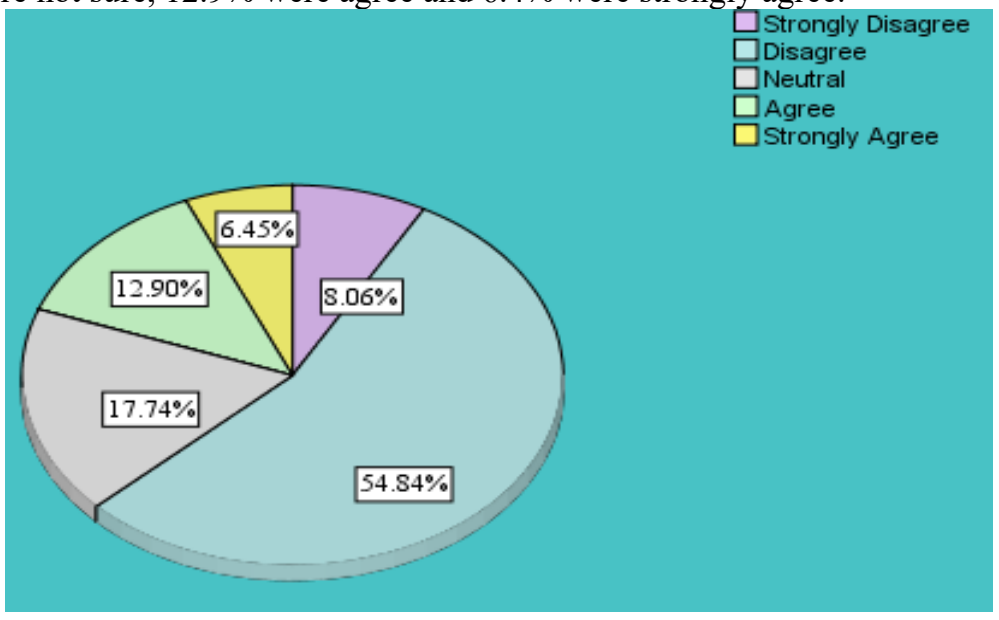

FIGURE 5.2

Q.No.5.3. Used books as reference sources.

Figure 5.3 portrays that $3.2 \%$ participants were strongly disagree the statement of using books as a reference source, disagreed by $17.7 \%$, not sured by $26.6 \%$, agreed by $46.7 \%$ and strongly agreed by $5.6 \%$.

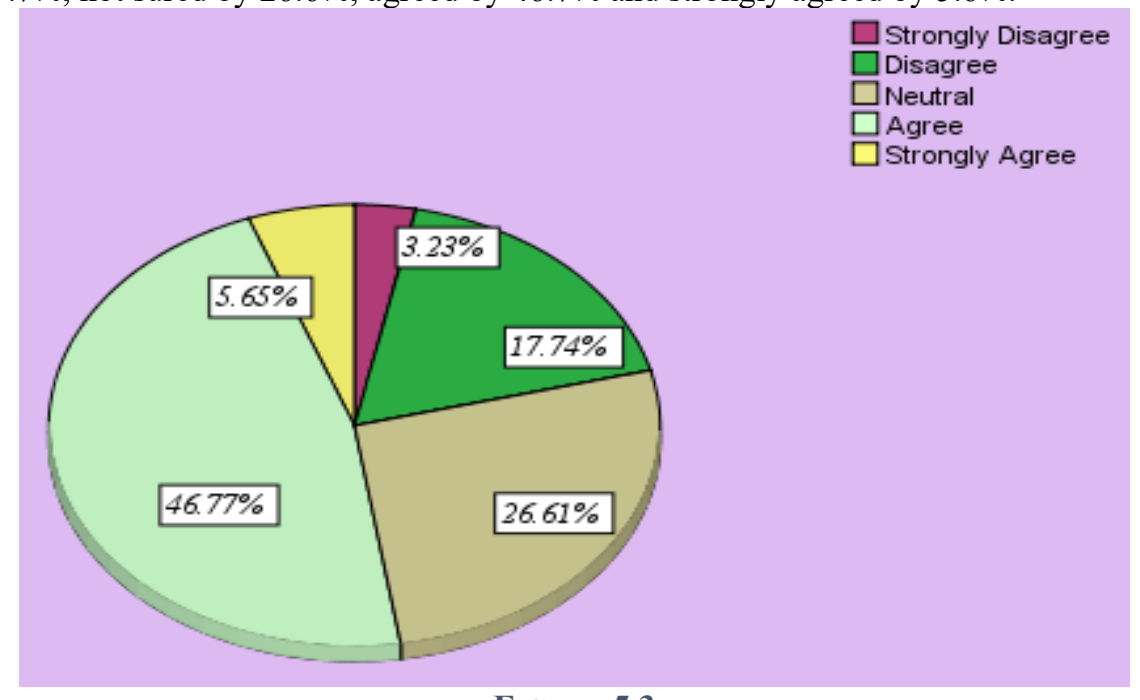

FIGURE 5.3 
Q.No.5.4: Found it easy to communicate.

Figure 5.5 evidences that the statement "found it easy to communicate" was strongly disagreed by $1.6 \%$, disagreed by $8.8 \%$, not sured by $25 \%$, agreed by $53.2 \%$ and strongly agreed by $11.2 \%$.

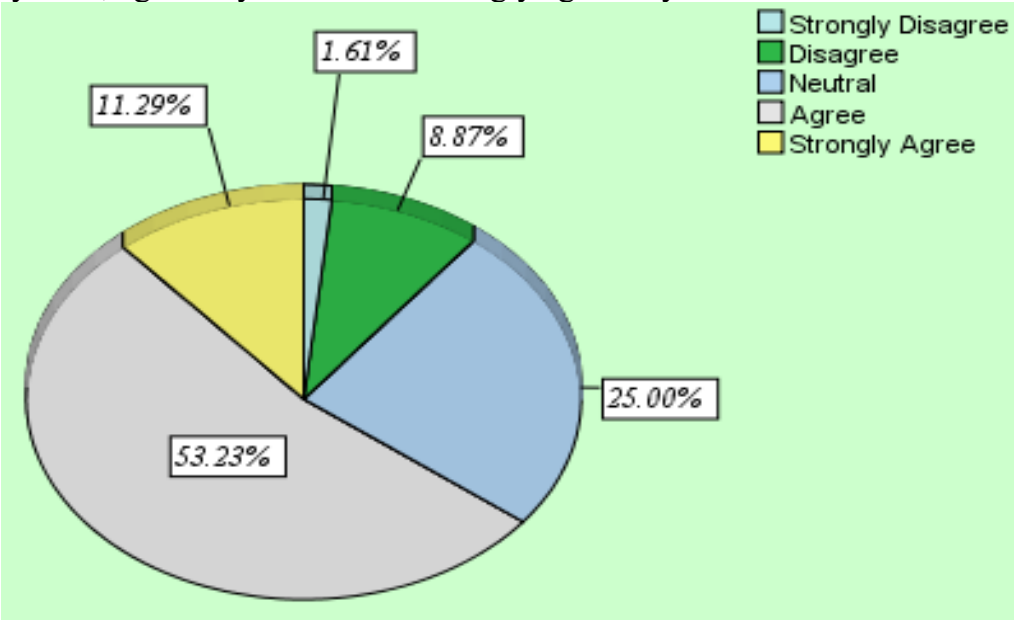

FIGURE 5.4

Q.No.5.5: Learned and executed it during undergraduate study.

Figure 5.5 shows that $1.6 \%$ participants strongly denied, $3.2 \%$ denied, $15.3 \%$ not sured, $55.6 \%$ agreed and $24.1 \%$ strongly agreed the statement of learning and executing it during undergraduate study.
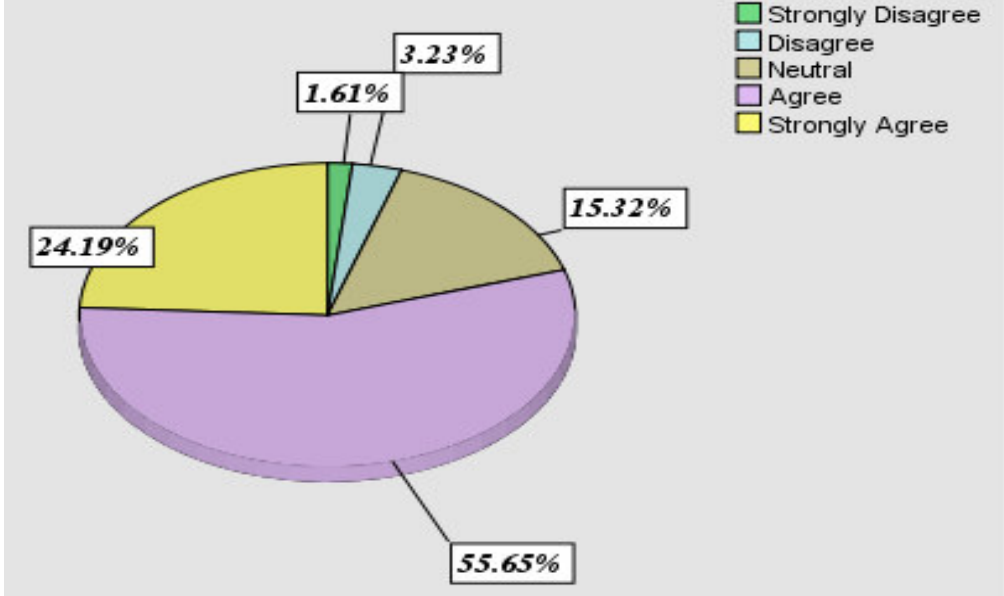

FIGURE 5.5

Q.No.5.6: Received theoretical-practical training in the hospital.

Figure 5.6 shows that $0.8 \%$ strongly denied, $4.8 \%$ denied, $9.6 \%$ not sured, $41.1 \%$ agreed and $43.5 \%$ strongly agreed about receiving theoretical practical training in the hospital.

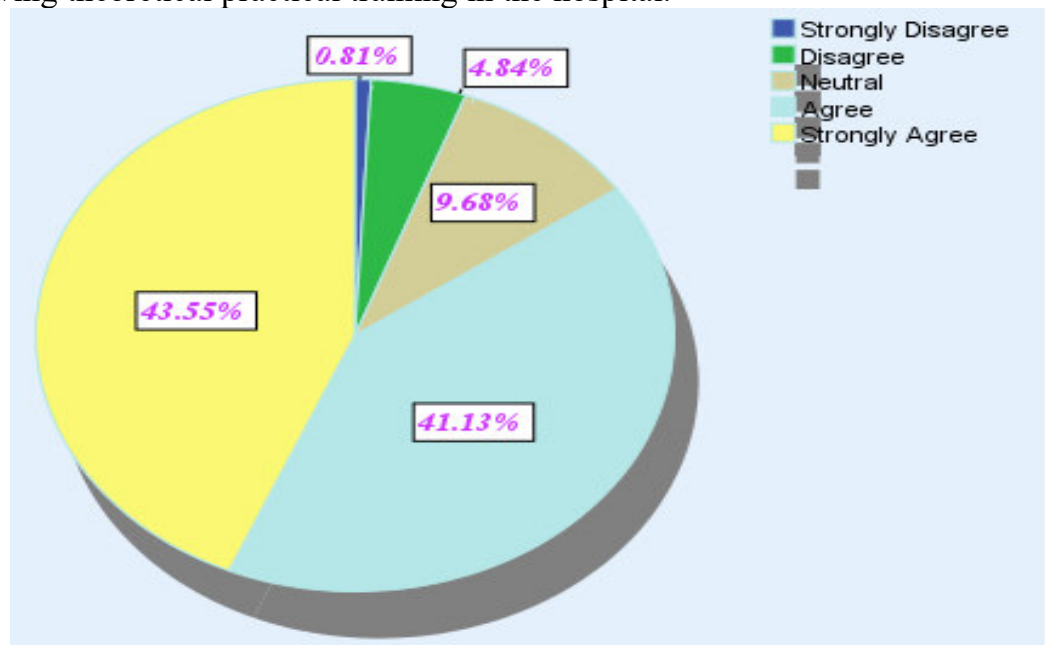

FIGURE 5.6 


\section{Q.No.5.7: Had the theoretical knowledge and practical experience.}

Figure 5.7 evidences that the statement "had theoretical knowledge and practical experience" was strongly denied by $0.8 \%$, denied by $1.6 \%$, not sured by $15.3 \%$, agreed by $34.6 \%$ and strongly agreed by $47.5 \%$ participants.

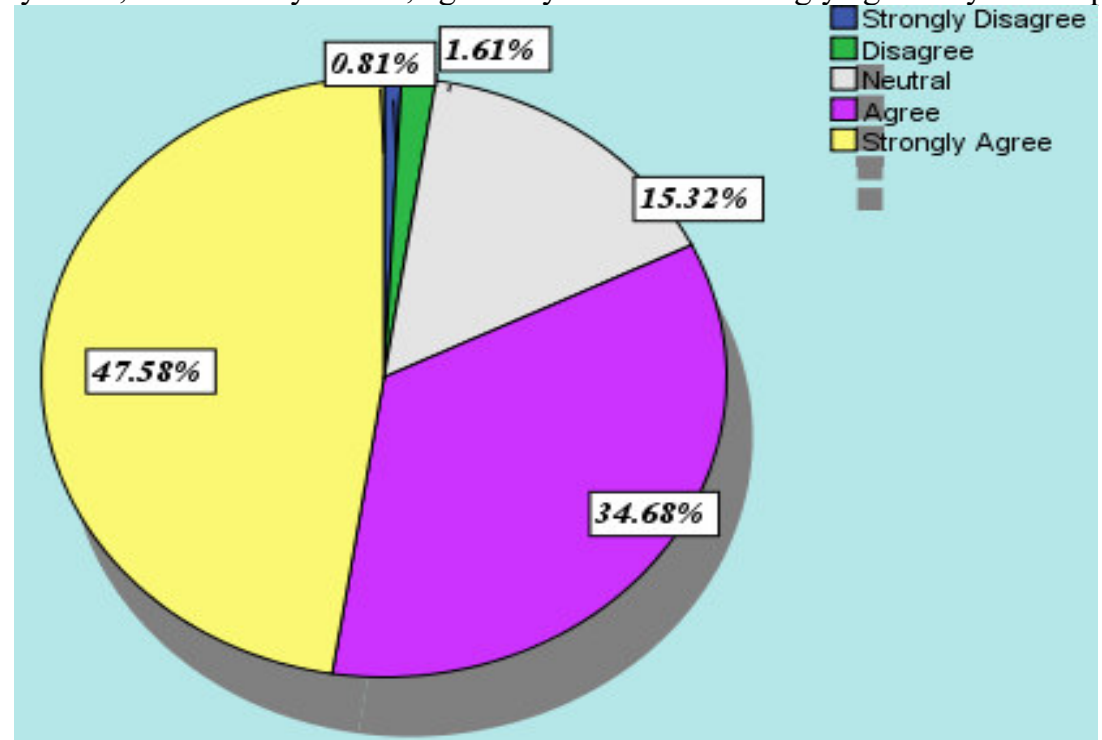

FIGURE 5.7

\section{DISCUSSION}

Nursing process is an integral part of nursing practices, and is of greater use in nursing care through which best nursing care can be delivered. The Purpose of this study is to know how many nurses implement it in daily routine and how many problems are faced by them. Moreover it also aims to find out how many feel it easy. A questionnaire was adopted from the base article by permission of the author. Questionnaire consisted of four main parts, first part consisted on demographics detail, second on previous experience and practices of the nurses regarding nursing process. Barriers encountered in execution of nursing process and facilitators for execution of nursing process also included in the next parts of questionnaire.

The results of current study displays that the total participants $n=124$, in which $0.8 \%$ of the participants were male and $99.2 \%$ participants were female. $37.1 \%$ participants from total were aged between $21-25$ years, $46.8 \%$ participants were aged between 26-30 years and 16.1\% participants were aged between 31-35 years. Participants included in study were holding degree and diploma and some were having both. $66.1 \%$ participants had nursing diploma, 29.8\% participants had Post RN degree and 5 participants had BSN degree. In this study mostly candidates were aged between 21-30 years so they were not too much experienced. $46 \%$ participants had 2-5 years' experience, $25.8 \%$ participants had 6-9 years' experience, $18.5 \%$ participants had $10-13$ years' experience, $8.9 \%$ participants had experience between 14-17 years and 8\% participants had experience between 18-21 years. The great number of participants were having age between 26 to 30 years, most of the participants were holding a nursing diploma and they were having a service experience between 2 to 5 years of age. This means that the most sample of this study were young adults having diplomas in nursing with a service experience less than 5 years.

Mostly nurses have a good knowledge in nursing process. In this study $89.52 \%$ (strongly agree \& agree) nurses have a good knowledge in nursing process and the knowledge gained mostly was from training school and colleges. Nursing process is a practice as well and most nurses also have gained knowledge from workshops and seminars too. According to study they have asked and suggested to enhance their knowledge but they need further information and lectures to practice the Nursing process accurately.

Nurses were confident and were able to apply Nursing process correctly without any confusion. About $46.7 \%$ nurses had a good knowledge on nursing process but they were finding it difficult to implement.

$51.6 \%$ nurses were strongly agree and $38.7 \%$ were agree to apply nursing process in routine. $48.3 \%$ nurses denied to leave it from nursing practices. More than 50 to $60 \%$ nurses used nursing process often. 70 to $74 \%$ nurses apply it daily in routine. Diploma nurses think that it's their duty to apply it and they have denied to leave it for higher degrees.

There are a lot of barriers which hinders the effectiveness of good application of nursing process. From the barriers point of view hospital management need to enlighten its use and $78.2 \%$ nurses have shown their positive behavior towards this. $73.3 \%$ were agree with statement of having insufficient equipment for its implementation.

This study has been carried out in a government hospitals, and in such hospitals nurses strength ratio to patients was inadequate. Workload was a greatest barrier. There was a workload. In a statement that nurses had no experience, $60.4 \%$ participants denied strongly the statement. They were unable to perform it effectively on all 
patients fully and equally was not carried out because according to $60.4 \%$ participants, it was time consuming. Along with implementation about 50 to $55 \%$ found it to require tedious documentation. $54 \%$ participants have suggested that there were some barriers related to resources, which were either insufficient or were not available at all. Barriers encountered during implementation were also related to administration. $63.7 \%$ participants were facing barriers related to nursing process.

There were many facilitators which nurses faced during implementation of nursing process. The brouchers, enough time, reference books, their previous theoretical knowledge, previous experience and their undertraining work guided and facilitated them a lot during execution of nursing process effectively. $53.2 \%$ nurses meant it a good source of communication between doctors and nurses.

In a study more than half $(86,58 \%)$ were diploma holders and $(95,62.7 \%)$ had worked for $>10 y r s$ at the hospital while Participants included in this study were holding degree and diploma and some were having both. 66.1\% participants had nursing diploma, 29.8\% participants had Post RN degree and 5 participants had BSN degree and $46 \%$ participants had 2-5 years' experience, $25.8 \%$ participants had 6-9 years' experience.(Kamau et al., 2016)

This study shows that $61.2 \%$ participants were have good knowledge in nursing process, $28.2 \%$ participants were agree but in another study results were somehow different from this study as the participant said that they had a good knowledge regarding Nursing Process. 37.2\% were strongly agreed to this statement and 57.4\% were agree. (Mahmoud \& Bayoumy, 2014)

This study shows that $51.6 \%$ participants had strongly agreed about getting knowledge from training college, $41.1 \%$ participants were agreed, and $51.6 \%$ participants were strongly agree to apply nursing process in patients care, $38.7 \%$ were agreed. Another study revealed that $81 \%$ of the participants received training in nursing process and $43 \%$ participants were capable of implementing the nursing process. (Mamseri \& Bezuidenhout, 2012)

A study showed that majority of nurses have poor knowledge about nursing process and no ability to write nursing care plan at their own. $35.5 \%$ of the respondents in this study were also agreed that they got knowledge from training College but $29.8 \%$ of the respondents' were not agreed (Wagoro \& Rakuom, 2015)

This study shows that $42.74 \%$ participants were strongly agree about getting knowledge from seminars or workshops, $37.90 \%$ were agree but a study showed a little similarity to current study where $92 \%$ participants were agreed, and Same study reported the respondents $81.3 \%$ agreed, they need more information and tutorials to apply the nursing process in patients' care. Also, 61, 81.3\% respondents disagreed that they should be left out of the nursing process practice; while 71, 94.7\% disagreed to the view that the application of the nursing process should be left for those with degree in Nursing. (Afolayan et al., 2013)

A study reported that $74.7 \%$ participants insisted that nurses can endure the tedious records that is essential for the application of the nursing process. Most of nurses specified that they had good knowledge of the nursing process from attended college as well as from seminars and workshops, which were carried out in their workplaces (Mahmoud \& Bayoumy, 2014)

\section{CONCLUSION AND SUMMARY}

The study is cross sectional descriptive study on barriers and facilitators during implementation of nursing process. The study is of great significance for participants and organization. Study was carried out in mayo hospital at a sample size of 124 nurses. Its purpose is to determine barriers and facilitators which nurses face during implementation of nursing process. A questionnaire was adopted from the author with her permission and through convenient sampling method all performas were filled and cross checked and collected. For analysis a software SPSS was used through which I checked mean, median, standard deviation and variance of all frequencies.

Validity and reliability of questionnaire was checked by KMO Bartlett's test and by Cronbach's alpha scale.

Through this study I came to know that $68 \%$ nurses in Mayo hospital were implementing nursing process often, $90 \%$ nurses had good knowledge and 19\% were implementing it because they had enough time for implementation and 15\% haven't implemented it ever, $65 \%$ nurses were unable to apply it efficiently because of shortage of time, $79 \%$ were not implementing it because of barriers related to administration, $74.2 \%$ related to resources and $89 \%$ were not implementing it because of overload of patients.

\section{Recommendations:}

1. Hospital administration should took such steps which will facilitate nurses in implementing nursing process.

2. Organizations should strictly include the implementation of nursing process in job descriptions of nurses.

3. Study can be conducted with correlation of barriers and facilitator to find out the relationship between barriers and implementation of nursing process

4. Quasi experimental study can also be conducted before and after an educational; session.

5. Hospital management may play an important role in provision of instruments and related materials which will ease nursing, the execution of nursing process.

6. Nurse patient strength ratio should be adequate so that all patients may receive good care. 


\section{Strengths of study}

1. Study findings of this study can only be generalized in teaching or tertiary level hospitals.

2. This study can be used as a base article for upcoming researchers in same hospital.

3. Data is consistent, short concise and real.

4. Data has been voluntarily collected.

Limitations of study:

1. The present study has been conducted in only one teaching hospital in Punjab so it cannot be generalized on all hospitals of Pakistan.

2. Study is a short time study.

\section{ANNEXURES}

Annexure A:

Action plan of Research project:

\begin{tabular}{|l|l|l|l|}
\hline Objectives & Activity/ Action & Target weeks & Status \\
\hline To select a topic for Project & $\begin{array}{l}\text { I selected a topic under } \\
\text { supervision of my supervisor }\end{array}$ & $1^{\text {st }}$ two weeks. & Done \\
\hline $\begin{array}{l}\text { To collect related articles, books, thesis and } \\
\text { develop literature review }\end{array}$ & $\begin{array}{l}\text { I collected data and developed } \\
\text { literature and referenced that }\end{array}$ & $3^{\text {rd }}$ and $6^{\text {th }}$ week & Done \\
\hline To develop full research synopsis & $\begin{array}{l}\text { I developed a synopsis and was } \\
\text { accepted by my supervisor }\end{array}$ & $6^{\text {th }}$ and $10^{\text {th }}$ week & Done \\
\hline Collect the data required & Collection and compilation of data & $11^{\text {th }}$ to $15^{\text {th }}$ week & Done \\
\hline To analyze and interpret data & Analysis and interpretation & $16^{\text {th }}$ and $19^{\text {th }}$ week & Done \\
\hline To draw a conclusion & $\begin{array}{l}\text { Conclusion and project } \\
\text { compilation }\end{array}$ & $20^{\text {th }}$ week & Done \\
\hline To develop a presentation for evaluation & Presentation \& evaluation & $21^{\text {st }}$ and $24^{\text {th }}$ week & Done \\
\hline
\end{tabular}

\section{Annexure B.}

Consent Form:

Description of the Research and Your Participation:

You are invited to participate in a research study conducted by Rukhsana Bibi. The purpose of this research is to study "the barriers and facilitators for execution of nursing process in surgical wards of Mayo hospital.

\section{Potential Benefits \& Confidentiality:}

Mention if there will be benefits to the participant that would result from their participation in this research. We will do everything we can to protect your privacy. Your identity will not be revealed in any publication resulting from this study.

\section{Voluntary Participation:}

Your participation in this research study is voluntary. You may choose not to participate and you may withdraw your consent to participate any time. You will not be penalized in any way should you decide not you participate or to withdraw from this study.

\section{CONSENT:}

I have read this consent form and have been given the opportunity to ask questions. I give my consent to participate in this study.

Participant's Signature or Participant's thumb stamp:

Date:

\section{Annexure C: \\ Questionnaire}

\section{Sharif college of Nursing, Lahore}

I am student of Post RN $2^{\text {nd }}$ Year from Sharif College of nursing Lahore, I am here to collect some data to complete my research on topic "Barriers and Facilitators for Execution of Nursing Process among Nurses from surgical wards of Mayo hospital Lahore. All the data I will collect from here will be kept confidential and will not be misuse. Your short time will be required to fill this questionnaire.

Name 
1. Demographic Data:

\begin{tabular}{|c|c|c|c|c|c|}
\hline Organization & & & Designation: & & \\
\hline Gender & & $\begin{array}{l}\text { Male } \\
\text { Female }\end{array}$ & Marital Status & & $\begin{array}{l}\text { Married } \\
\text { Single }\end{array}$ \\
\hline Age Group & & $\begin{array}{l}21-27 \\
28-35\end{array}$ & Qualification & $\begin{array}{l}0 \\
0 \\
0 \\
0\end{array}$ & $\begin{array}{l}\text { Nursing diploma } \\
\text { Midwifery diploma } \\
\text { Post RN/ BSN } \\
\text { Other }\end{array}$ \\
\hline Experience in Organization & $\begin{array}{l}\circ \\
\circ \\
\circ \\
\circ \\
\circ\end{array}$ & $\begin{array}{l}2 \text { to } 7 \text { years } \\
8 \text { to } 13 \text { years } \\
14 \text { to } 19 \text { years } \\
20 \text { to } 25 \text { years }\end{array}$ & & & \\
\hline
\end{tabular}

2. Previous Experiences and Practices of the Nurses Regarding Nursing Process (NP)

\begin{tabular}{|c|l|l|l|l|l|l|}
\hline S. No & Variables & $\begin{array}{l}\text { Strongly } \\
\text { agree }\end{array}$ & agree & neutral & disagree & $\begin{array}{l}\text { Strongly } \\
\text { disagree }\end{array}$ \\
\hline 1. & Nurses views about their Nursing Process knowledge & & & \\
\hline$\circ$ & $\begin{array}{l}\text { I have good knowledge in Nursing } \\
\text { process. }\end{array}$ & & & & & \\
\hline$\circ$ & I got knowledge from training College. & & & & & \\
\hline$\circ$ & $\begin{array}{l}\text { I got knowledge from } \\
\text { seminars/workshops. }\end{array}$ & & & & \\
\hline$\circ$ & $\begin{array}{l}\text { I need more information and tutorials to } \\
\text { practice Nursing process. }\end{array}$ & & & & & \\
\hline 2. & Perceived confidence in application of nursing process: & & & \\
\hline$\circ$ & $\begin{array}{l}\text { I am able to apply Nursing process } \\
\text { correctly }\end{array}$ & & & & \\
\hline$\circ$ & $\begin{array}{l}\text { I understand Nursing process but found it } \\
\text { difficult to implement }\end{array}$ & & & & & \\
\hline$\circ$ & I found it confusing & & & & \\
\hline 3. & Acceptability and willingness to practice the nursing process by nurses: & & \\
\hline$\circ$ & $\begin{array}{l}\text { I am willing to apply Nursing process in } \\
\text { patients' care }\end{array}$ & & & & \\
\hline$\circ$ & $\begin{array}{l}\text { I will prefer to be left out of this Nursing } \\
\text { process practice }\end{array}$ & & & & & \\
\hline$\circ$ & I practice the nursing process often & & & & & \\
\hline$\circ$ & I have never practiced the nursing process & & & & & \\
\hline$\circ$ & $\begin{array}{l}\text { Application of it should be left for higher } \\
\text { nursing degrees }\end{array}$ & & & & \\
\hline
\end{tabular}


3. Barriers Encountered in Execution of the Nursing Process.

\begin{tabular}{|l|l|l|l|l|l|l|}
\hline S. No & Variables & $\begin{array}{l}\text { Strongly } \\
\text { agree }\end{array}$ & agree & neutral & Disagree & $\begin{array}{l}\text { Strongly } \\
\text { disagree }\end{array}$ \\
\hline 1. & $\begin{array}{l}\text { Hospital management needs to be } \\
\text { enlightened on its benefits }\end{array}$ & & & & \\
\hline 2. & $\begin{array}{l}\text { Insufficient equipment for the } \\
\text { implementation of nursing process }\end{array}$ & & & & & \\
\hline 3. & $\begin{array}{l}\text { The nursing staff strength to patient ratio is } \\
\text { inadequate to fully practice the nursing } \\
\text { process (Workload) }\end{array}$ & & & & & \\
\hline 4. & $\begin{array}{l}\text { A nurse cannot see any purpose for writing } \\
\text { the care plan }\end{array}$ & & & & & \\
\hline 5. & Not being able to follow patients & & & & & \\
\hline 6. & Staff had no experience in nursing process & & & & & \\
\hline 7. & Nursing process is time consuming & & & & & \\
\hline 8. & $\begin{array}{l}\text { Nursing process requires tedious (too long) } \\
\text { documentation }\end{array}$ & & & & & \\
\hline 9. & Barriers related to resources & & & & & \\
\hline 10. & Barriers related to administration & & & & & \\
\hline 11. & Barriers related to nursing process & & & & & \\
\hline
\end{tabular}

4. Facilitators for Execution of Nursing Process.

\begin{tabular}{|l|l|l|l|l|l|l|}
\hline S No. & Variables & $\begin{array}{l}\text { Strongly } \\
\text { agree }\end{array}$ & agree & Neutral & Disagree & $\begin{array}{l}\text { Strongly } \\
\text { disagree }\end{array}$ \\
\hline 1. & Had adequate brochures in the unit & & & & & \\
\hline 2. & $\begin{array}{l}\text { Had enough time for performing the } \\
\text { phase }\end{array}$ & & & & & \\
\hline 3. & Used books as reference sources & & & & & \\
\hline 4. & Found it easy to communicate & & & & & \\
\hline 5. & $\begin{array}{l}\text { Learned and executed it during } \\
\text { undergraduate study }\end{array}$ & & & & & \\
\hline 6. & $\begin{array}{l}\text { Received theoretical-practical } \\
\text { training in the hospital }\end{array}$ & & & & & \\
\hline 7. & $\begin{array}{l}\text { Had the theoretical knowledge and } \\
\text { practical experience }\end{array}$ & & & & & \\
\hline
\end{tabular}


Annexure D:

Permission to collect data:

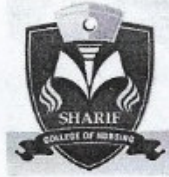

Sharif College of Nursing, Lahore.

Jati Umra, Sharif Medical City Road, Lahore

Tel: 042-37860101-04, Ext. 342 Fax: 042-37860180

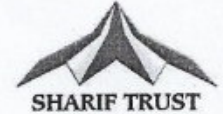

SHARIF TRUST

August $9^{\text {th }}, 2019$

Dr. Tahir Khalil

Chief Executive Officer,

Medical Superintendent,

Mayo Hospital Lahore.

\section{RE: Institutional consent for conducting research.}

Dear Sir,

Miss Rukhsana Student of Post RN BSN programme at Sharif College of Nursing is conducting a research on "Barriers and Facilitators for Execution of Nursing Process among Nurses in Mayo Hospital Lahore". The purpose of this study is to identify the barriers by which nurses didn't use Nursing process to prepare a nursing care plane.

Nursing Process include Assessment, Diagnosis, planning, implementation and after all evaluation, this process should be done for every individual patient to prepare an ideal nursing care plan according to his/her disease process

The study finding will help the organization to know about the specific barrier by which nurses didn't make a proper nursing care plane by using nursing process. By knowing the barriers which make a hurdle for nursing process, organization can abide that barriers to improve nursing practice and improve quality care.

All the Nurses who are working in surgical wards in your well reputed hospital are meeting the inclusion criteria of the study, will be required to fill a self-administered questionnaire which would take maximum 10 minutes to assist the accurate collection of data/information.

Looking forward for your permission and support in this research at Mayo Hospital Lahore

Yours Sincerely

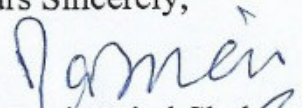

Ms. Razia Iqbal Shah?

Principle Sharif College of Nursing

Sharif Medical City

Jati Umrah Lahore
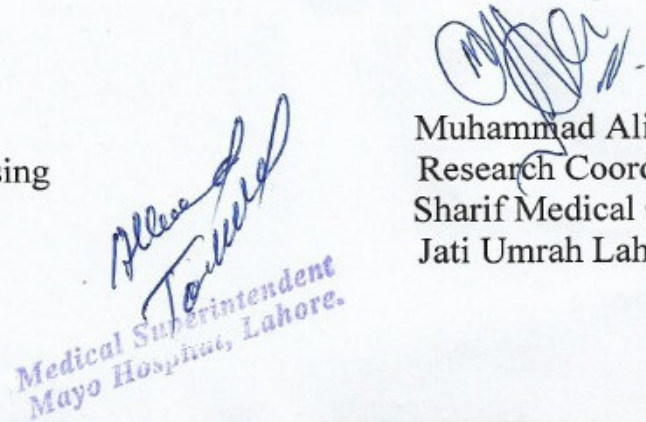

Muhammad Ali

Research Coordinator

Sharif Medical City

Jati Umrah Lahore

\section{REFERENCES:}

Afolayan, J. A., Donald, B., Baldwin, D. M., Onasoga, O., \& Babafemi, A. (2013). Evaluation of the utilization of nursing process and patient outcome in psychiatric nursing: case study of psychiatric hospital Rumuigbo, Port Harcourt. Adv Appl Sci Res, 4(5), 34-43.

Agyeman-Yeboah, J., Korsah, K. A., \& Okrah, J. (2017). Factors that influence the clinical utilization of the 
nursing process at a hospital in Accra, Ghana. BMC nursing, 16(1), 30.

Akhtar, S., Hussain, M., Afzal, M., \& Gilani, S. A. (2018). Barriers and Facilitators for Execution of Nursing Process among Nurses from Medical and Surgical Wards in a Public Hospital Lahore. International Journal of Social Sciences and Management, 5(3), 170-186.

Barra, D. C. C., Dal Sasso, G. T. M., \& Baccin, C. R. A. (2014). Warning systems in a computerized nursing process for Intensive Care Units. Revista da Escola de Enfermagem da USP, 48(1), 125-132.

Farahani, Z. B., Rastian, M., Rassouli, M., \& Sarbakhsh, P. (2016). The Impact of Training on Nursing Process Implementation Skills of Surgical Ward Nurses. INTERNATIONAL JOURNAL OF MEDICAL RESEARCH \& HEALTH SCIENCES, 5(7), 268-272.

Guedes, E. d. S., Turrini, R. N. T., Sousa, R. M. C. d., Baltar, V. T., \& Cruz, D. d. A. L. M. (2012). Attitudes of nursing staff related to the nursing process. Revista da Escola de Enfermagem da USP, 46(SPE), 130-137.

Hagos, F., Alemseged, F., Balcha, F., Berhe, S., \& Aregay, A. (2014). Application of nursing process and its affecting factors among nurses working in mekelle zone hospitals, Northern Ethiopia. Nursing research and practice, 2014.

Kamau, M., Maingi, N., Ndungu, E., \& Karonjo, J. (2016). Implementation of Nursing Process among Nurses Working In In-Patients Wards in Rift Valley Provincial General Hospital, Nakuru County, Kenya.

Kelly, L. A., Wicker, T. L., \& Gerkin, R. D. (2014). The relationship of training and education to leadership practices in frontline nurse leaders. Journal of Nursing Administration, 44(3), 158-163.

Mahmoud, M. H., \& Bayoumy, H. M. (2014). Barriers and facilitators for execution of nursing process from nurses' perspective. International Journal of Advanced Research, 2(2), 300-315.

Mamseri, R. A., \& Bezuidenhout, M. (2012). The nursing process as a means of improving patient care. University of South Africa,

Mbithi, B. W., Mwenda, C. S., \& Karonjo, J. (2018). Observed Utilization of the Nursing Process among Nurses in Selected Public Health Care Facilities in Kenya. International Journal of Nursing, 8(5), 77-82.

Momoh, M., \& Chukwu, D. (2010). Factors that militante against the use of nursing. J Wilolud, 4, 6-9.

Semachew, A. (2018). Implementation of nursing process in clinical settings: the case of three governmental hospitals in Ethiopia, 2017. BMC research notes, 11(1), 173.

Wagoro, M. C. A., \& Rakuom, C. P. (2015). Mainstreaming Kenya-Nursing Process in clinical settings: the case of Kenya. International Journal of Africa Nursing Sciences, 3, 31-39.

Zamanzadeh, V., Valizadeh, L., Tabrizi, F. J., Behshid, M., \& Lotfi, M. (2015). Challenges associated with the implementation of the nursing process: A systematic review. Iranian journal of nursing and midwifery research, 20(4), 411. 